\title{
Analysis of mice brain and SH-SY5Y neuroblastoma cell proteome by quantitative two-dimensional electrophoresis
}

\author{
Ph.D. thesis \\ István Földi \\ Department of Medical Chemistry \\ University of Szeged
}

Supervisors:

Prof. Botond Penke

Dr. Tamás Janáky

Szeged

2011. 


\section{List of publications}

Original full papers, directly related to the subject of the thesis:

Charaterisation of the variation of mouse brain proteome by two-dimensional electrophoresis

Földi I, Müller G, Penke B, Janáky T

J Proteomics (2011), 74:894-901 doi:10.1016/p.prot.2011.03.006 (IF: 3.851)

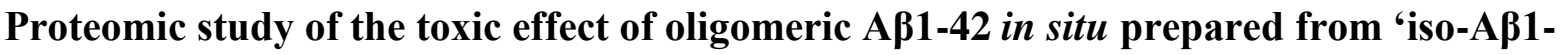
$42^{\prime}$

Földi I, Datki ZL, Szabó Z, Bozsó Z, Penke B, Janáky T

J Neurochem (2011), 117:691-702, doi:10.1111/j.1471-4159.2011.07238.x (IF: 3.999)

Review article, directly related to the thesis:

Systems biology of Alzheimer's disease: How diverse molecular changes result in memory impairment in AD

Juhász G, Földi I, Penke B

Neurochem Int (2011), 58:739-750, doi:10.1016/j.neuint.2011.02.008 (IF: 3.541)

Original full papers, not directly related to the subject of the thesis:

NO-sensitive guanylyl cyclase beta 1 subunit is peripherally associated to chromosomes during mitosis. Novel role in chromatin condensation and cell cycle progression

Pifarré P, Baltrons MA, Földi I, Garcia A

Int J Biochem Cell Biol (2010), 41:1719-1730, doi:10.1016/j.biocel.2009.02.022 (IF: 4.887)

Characterisation of the interaction between amyloid-beta 1-42 and glyceraldehide phosphodehydrogenase Verdier Y, Földi I, Sergeant N, Fülöp L, Penke Zs, Janáky T, Szücs M, Penke B

J Pept Sci (2009), 14:755-762, doi:10.1002/psc.998 (IF: 1.807)

Differences between normal and alpha-synuclein overexpressing SH-SY5Y neuroblastoma cells after $A \beta(1-42)$ and NAC treatment

Hunya Á, Földi I, Szegedi V, Soós K, Zarándi M, Szabó A, Zádori D, Penke B, Datki ZL

Brain Res Bull (2009), 75:648-654, doi:10.1016/j.brainresbull.2007.10.035 (IF: 2.184) 


\section{Abbreviations}

2D-DIGE two-dimensional difference gel electrophoresis

2-DE

$\mathrm{AD}$

APP

$\mathrm{A} \beta$

BSA

CBB

CCD

CHAPS

CSF

CV

CyDye

DMSO

DRP-2

DTE

EEF-2

ER

ESI

FDR

GO

GSK-3

hnRNP K

Hsp70

IAA

ICAT

IEF

IPG

iTRAQ

MALDI

MS

MS/MS

$\mathrm{Mw}$

NFT

NMDA-R

PBS

PDH

PDHE1-B

$\mathrm{p} I$

PMF

PMT

Q

RNS

ROS

RuBPs

SD

SDS-PAGE

SGoF

SILAC

TBS

TCA

TOF

UPR two-dimensional electrophoresis

Alzheimer's disease

amyloid precursor protein

amyloid-beta

bovine serum albumine

Coomassie brilliant blue

charge coupled device

3-(cyclohexylamino)-1-propanesulphonic acid

cerebrospinal fluid

coefficient of variation

cyanine dye

dimethyl sulfoxide

dihidropyrimidinase related protein-2

dithioerythritol

eukaryotic elongation factor-2

endoplasmic reticulum

electrospray ionisation

false discovery rate

gene ontology

glycogen synthase kinase-3

heterogenous nuclear ribonucleoprotein $\mathrm{K}$

Heat shock protein 70

iodacetamide

isotope-coded affinity tag

isoelectric focusing

immobilized $\mathrm{pH}$ gradient

isobaric tags for relative and absolute quantitation

matrix assisted laser desorption ionisation

mass spectrometry

tandem mass spectrometry

molecular weight

neurofibrillary tangle

$N$-methyl-D-aspartate receptor

phosphate-buffered saline

pyruvate dehydrogenase

pyruvate dehydrogenase E1 component subunit beta

isoelectric point

peptide mass fingerprint

photomultiplier

quadrupole

reactive nitrogen species

reactive oxygen species

ruthenium bathophenantroline disulfonate

standard deviation

sodium dodecyl sulphate-polyacrylamide gel electrophoresis

sequential goodness of fit

stable isotope labelling with amino acids in cell culture

tris-buffered saline

tricarboxylic acid cycle

time of flight

unfolded protein response 


\section{Table of contents}

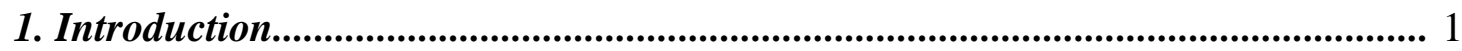

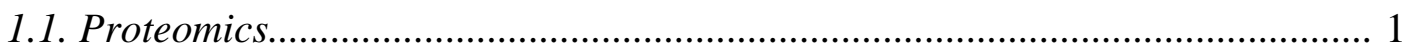

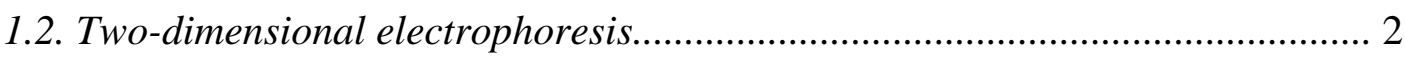

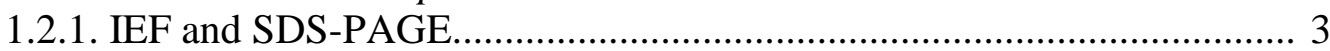

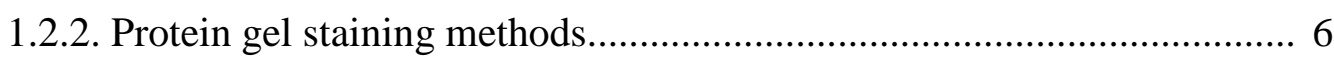

1.2.3. Image acquisition and analysis....................................................... 8

1.2.4. Experimental design and statistical analysis of a 2-DE study.............. 9

1.2.5. Limitations and future prospects of 2-DE........................................... 12

1.2.6. MS-based protein identification after 2-DE separation........................... 13

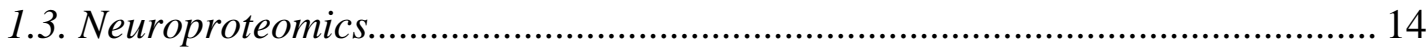

1.3.1. Cellular and neuropathological events of AD...................................... 14

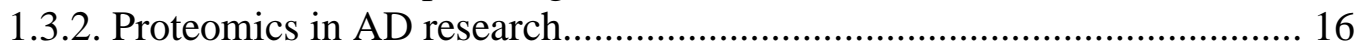

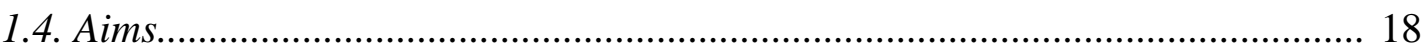

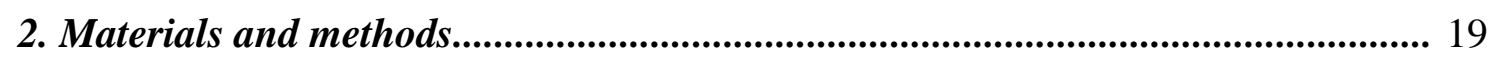

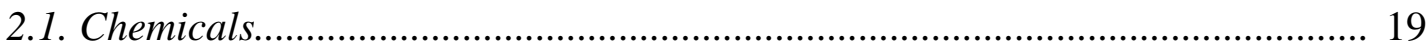

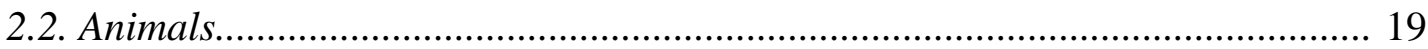

2.3. Cell culture and oligomeric AB1-42 treatment.................................................. 20

2.4. Experimental details for 2-DE analysis of mouse brain proteome................... 20

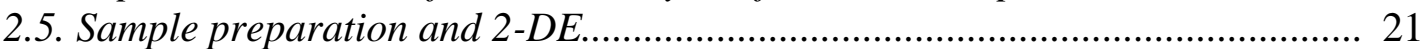

2.5.1. 2-DE analysis of mouse brain proteome............................................. 21

2.5.2. Oligomeric A $\beta 1-42$ treated SH-SY5Y cells........................................ 22

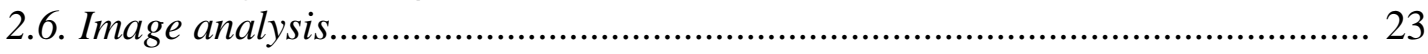

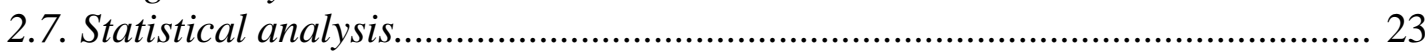

2.7.1. 2-DE analysis of mouse brain proteome............................................. 23

2.7.2. Oligomeric A $\beta 1-42$ treated SH-SY5Y cells.......................................... 24

2.8. Mass spectrometric analysis and protein identification..................................... 24

2.9. Quantification of Hsp70 and EEF-2 by Western blot.................................... 25

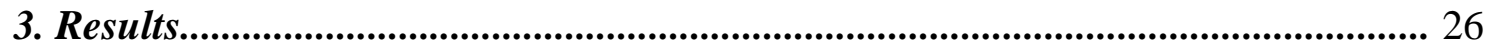

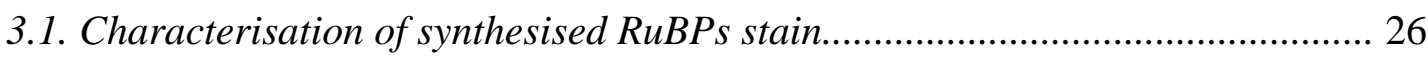

3.2. 2-DE analysis of mouse brain proteome ...................................................... 27

3.2.1. Technical and biological variations.................................................. 27

3.2.2. Detection of significant protein expression differences between

NMRI mouse groups........................................................................... 31

3.2.3. Comparison of NMRI mouse stock and C3H/HEN mouse strain............ 32

3.3. Proteomic study of the effect of oligomeric AB1-42 on SH-SY5Y cell line......... 32

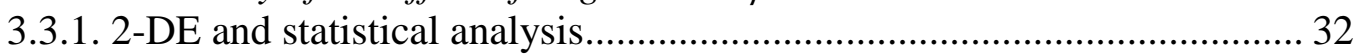

3.3.2. Classification of identified proteins.................................................. 39

3.3.3. Validation of Hsp70 and EEF-2 expression by Western blot analysis..... 39

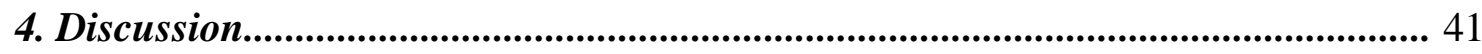

4.1. 2-DE analysis of mouse brain proteome ......................................................... 41

4.2. Proteomic study of the effect of oligomeric AB1-42 on SH-SY5Y cell line......... 44

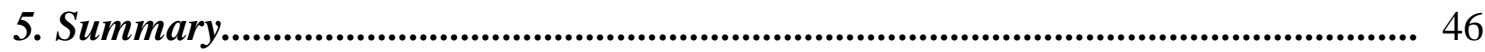

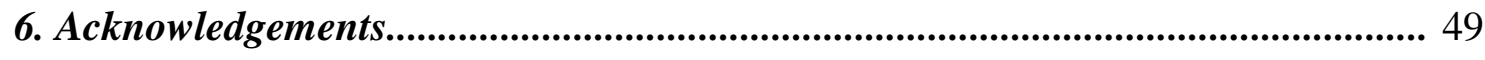

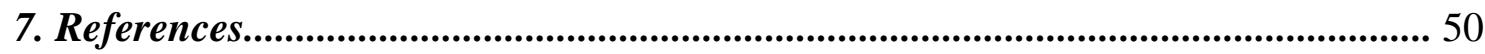




\section{Introduction}

\subsection{Proteomics}

In the last decade the biggest revolution of the molecular biology was the completion of the sequencing the human genome (Lander et al. 2001, Venter et al. 2001). In addition, the genome sequences of important model systems used in biological, medical and pharmacological experiments are also available (Waterston et al. 2002, Gibbs et al. 2004). After genome sequencing studies, the focus was shifting to transcriptomics and proteomics. Transcriptomics studies the levels of transcripted mRNA (transcriptome) in cells or tissues. Proteomics is initially concerned with determining the structure, expression, localization, biochemical activity, interactions and cellular roles of as many proteins as possible (de Hoog and Mann, 2004). In other words, proteomics is a large-scale study of the proteome.

The term 'proteome' was described in the 1990's: the PROTEin complement expressed by a genOME (Wilkins et al. 1996). The cellular proteome is a dynamic and complex network of proteins. Due to the fact that only a fraction of mRNA is translated to proteins, mRNA levels are relatively weak predictors of protein levels (Gygi et al. 1999). In addition, the alternative splicing of the gene transcription process and the numerous posttranslation modifications (e.g., phosphorylation, glycosylation, ubiquitination and methylation) also influence the behaviour of the proteins. Thus, transcriptome profiling is necessary, but insufficient for comprehensive delineation of a biological system (Nie et al. 2007). Biological functions are mainly carried out by the dynamic populations of proteins determined by gene expression regulation and affected by environmental factors.

Recent proteomic technologies have limitations. The 23,000 human genes encode several hundred thousand proteins due the alternative splicing of gene transcription process and post-translational protein modifications. The number of unique protein species in a proteome of a single mammalian cell type is not well defined but is likely to be at least 10,000-20,000 (Zuo et al. 2001). In contrast with this, the highest resolution proteomic technologies can only detect a few thousands proteins. In addition, the dynamic range of protein concentrations within a cell or tissue is very high. In an eukaryotic cell, the difference in abundance between the most highly expressed and the least expressed proteins ranges over 6 orders of magnitude (Rabilloud 2002). Most of the proteomic samples are dominated by several highly abundant protein classes (e.g., actin, tubulin, albumin etc.). Thus, in a 
quantitative proteomic study the identified proteins belong to the 1000-2000 most abundant proteins. This fact makes it difficult to detect and analyse the low-abundant proteins even if they may have a determinative function in a biological system. These low-abundant proteins are quantitatively accessible only when they are analysed in a targeted approach, such as enzyme-linked immunosorbent assay and targeted mass spectrometric (MS) analysis, or when they become high-abundant by fractionation of a protein sample or depletion of the most abundant proteins (Meyer and Stühler, 2007). Because of detection limits of proteomic technologies such as two-dimensional electrophoresis (2-DE), the same proteins seem to predominate in different studies regardless of the experiment, tissue or species (Petrak et al., 2008). The biggest challenge for quantitative proteomics is to analyse serum samples. Serum has an extraordinary dynamic range in that more than 10 orders of magnitude in concentration separate albumin to the rarest proteins (Anderson and Anderson, 2002). Despite the daunting analytical problems serum proteome analysis is widespread in biomarker discovery studies.

Quantitative proteomics aims at establishing differences in the proteome profiles from a qualitative and quantitative point of view between individuals or populations, and to identify protein species which exhibit changes in expression or post-translational modifications in response to a given stimuli (Karp and Lilley 2007, Valledor and Jorrín 2011). Recently several modern and high-resolution quantitative proteomic technologies are available. These fall into two major categories: (a) gel-based methods, mainly 2-DE and (b) MS-based measurements, such as 'stable isotope labelling with amino acids in cell culture' (SILAC), 'isotope-coded affinity tag' (ICAT), 'isobaric tags for relative and absolute quantitation' (iTRAQ) and label-free approaches (Yan and Chen 2005). In proteomics, a significant portion of the accumulated data has been obtained from quantitative 2-DE. Despite the many technical improvements this method is not automated and requires proficiency to get reliable and valid information. Thus, in this dissertation I will put a special emphasis on quantitative 2-DE, discussing the basic principles, advantages and limitations of this technique.

\subsection{Two-dimensional gel-electrophoresis}

2-DE is the most frequently used technique in quantitative proteomics which was first described in 1975 (O'Farrel 1975). 2-DE is the highest resolution of all separation techniques for intact proteins in a single analytical run. 2-DE can typically resolve hundreds-to-thousands of individual protein species using two orthogonal separations: isoelectric focusing (IEF; first 
dimension) and sodium dodecyl sulphate-polyacrylamide gel electrophoresis (SDS-PAGE; second dimension) (Friedman et al. 2009).

\subsubsection{IEF and SDS-PAGE}

IEF is an electrophoretic separation technique to separate amphoteric molecules according to their net charge as defined by the $\mathrm{pK}_{\mathrm{a}}$ values of proton-accepting sites within a molecule. For proteins and peptides, these sites can be found in the free amines and carboxylic acids located at the $\mathrm{N}$ - and C-termini as well as on the side chains of arginine, lysine, histidine, aspartic acid and glutamic acid residues. Thus, the net charge of a protein or peptide is determined by the amino acid composition and the $\mathrm{pH}$ of the environment. The isoelectric point $(\mathrm{p} I)$ is a physicochemical parameter of an amphoteric molecule defined as the $\mathrm{pH}$ that a molecule has a neutral net charge. Proteins that are located in a position in the $\mathrm{pH}$ gradient that is lower (more acidic) than their $\mathrm{p} I$ will be positively charged. Conversely, proteins located in a position more basic than their $\mathrm{p} I$ will have negative net charge. In an electric field a protein migrates towards the opposite sign of its net charge. Because it migrates in a $\mathrm{pH}$ gradient it will stop migrating at the $\mathrm{p}$, as it has zero net charge (Figure 1.) The method has an 'in-built' focusing effect: at the $\mathrm{p} I$ of a protein it should diffuse away, thus it will become charged again, therefore the electric field forces it to migrate back to the $\mathrm{p} I$ (Westermeier and Naven 2002, Friedman et al. 2009).

In practice there are two ways to establish $\mathrm{pH}$ gradient for IEF:

- $\mathrm{pH}$ gradient formed in an electric field by amphoteric buffers, called carrier ampholytes.

- Immobilized $\mathrm{pH}$ gradient in which the buffering groups are linked to the gel matrix.

Originally the carrier ampholytes generated $\mathrm{pH}$ gradient was used for IEF for 2-DE. The result of the synthesis of heterogeneous mixture of isomers of aliphatic oligoaminooligocarboxylic acids is a spectrum of low molecular weight amphloytes with closely neighbouring $\mathrm{p} I \mathrm{~s}$ and with high buffering capacities at their $\mathrm{p} I$ (Vesterberg 1966). The charged ampholytes migrate in an electric field according to their charges and when they reach their $\mathrm{p} I$ they lose their charges and buffer the $\mathrm{pH}$ value at their $\mathrm{p} I$. (Westermaier and Naven 2002). The real method of using ampholyte mixture for separating proteins in polyacrylamide gel was first described in the early 1970's (Vesterberg 1972, Righetti and 
Drysdale 1973). Carrier ampholytes generated $\mathrm{pH}$ gradient was also used to perform the first high-resolution 2-DE in 1975 (O’Farrel 1975).

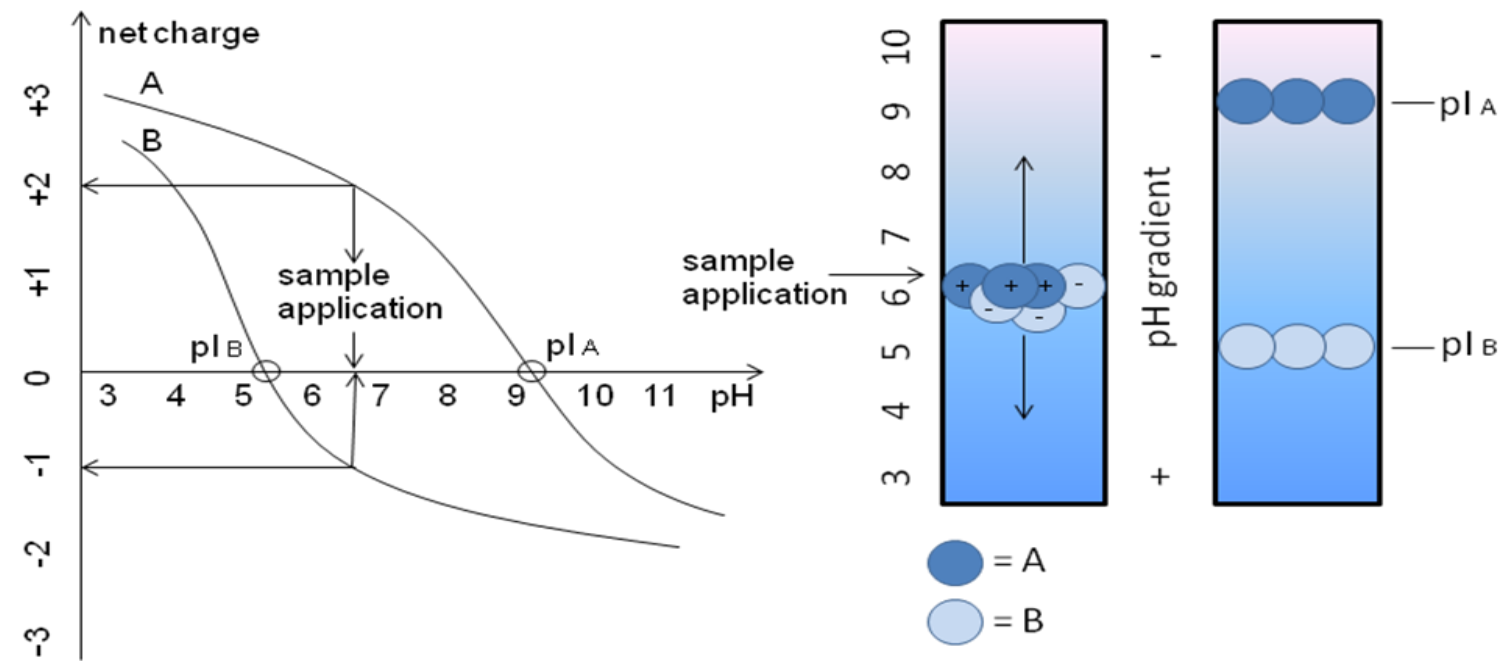

Figure 1. The basic principle of isoelectric focusing. Left: net charge curves of two model proteins A and B. At the point of sample application, A will have two positive, B will have one negative charge(s). Right: migration of $\mathrm{A}$ and $\mathrm{B}$ to their $\mathrm{p} I \mathrm{~s}$ in the $\mathrm{pH}$ gradient of an isoelecric gel. Figure adopted from Westermeier and Naven, 2002.

Despite the early success of carrier ampholytes generated $\mathrm{pH}$ gradient IEF, the reproducibility of this method was poor due to the $\mathrm{pH}$ gradient instability (gradient drift, especially in the cathodic part, so called 'cathodic drift') over long focusing time. One of the major improvements in 2-DE was the introduction of immobilized $\mathrm{pH}$ gradient (IPG) within a polyacryalmide matrix for IEF. IPGs are based on the bifunctional 'immobiline' reagents, which are acrylamide derivatives with the general structure $\mathrm{CH}_{2}=\mathrm{CH}-\mathrm{CO}-\mathrm{NH}-\mathrm{R}$, where the $\mathrm{R}$ contains either a carboxyl or a tertiary amino group. The $\mathrm{pH}$ gradient gels are cast similarly to the gradient gels, but the "heavy" and "light" solutions are adjusted to different pH values with the aid of the 'immobiline' buffers. IPGs show a number of advantages compared with carrier ampholyte generated $\mathrm{pH}$ gradients: (1) the cathodic drift is completely abolished; (2) they give higher resolution and higher loading capacity; (3) they have uniform conductivity and buffering capacity; (4) they represent a milieu of known and controlled ionic strength (Bjellqvist et al. 1982). The development of the modern IPG gel strips went through a long journey until the industrial production of the first IPG DryStrips started in 1991 (Görg et al. 2009). Commercially produced IPG strips are cast on a covalently bound film backing. The 
strips are then dried for long-term storage at $-20^{\circ} \mathrm{C}$. Carrier ampholytes are still used for improving conductivity and protein solubility (Friedman et al. 2009). Recently, IPG DryStrips are available in different sizes and $\mathrm{pH}$ gradients from several vendors.

For second dimension SDS-PAGE is the method a choice. SDS-PAGE was described in 1970 and has long been the most frequently used technique for separating intact proteins according to their molecular weight (Mw) for various biochemical studies (Laemmli 1970). By adding SDS to a protein solution in excess, the SDS and proteins form complexes (Ibel et al. 1990).

The formed anionic complexes have a roughly constant negative charge per unit mass. During the electrophoresis these negatively charged complexes migrate towards the anode. Secondary and tertiary structures of the proteins are disrupted and the polypeptides become unfolded. Usually a reducing agent, such as dithiothreitol or $\beta$-mercatoethanol is added to the sample to cleave the disulfide bridges between cysteins. The electrophoretic mobility of the proteins depends largely on the molecular weight, but can be influenced by protein hydrophobicity. At a certain polyacrylamide percentage there is an approximately linear relationship between the logarithm of molecular weights and migration distance. With the help of comigrated $\mathrm{Mw}$ standard proteins, the unknown molecular weight can be estimated. Polyacrylamide gels are polymerised from acrylamide monomers and cross-linking reagent, such as N,Nmethylenbisacrylamide or piperazine-diacrylamide. The pore size can be controlled by total acrylamide concentration $(\mathrm{T})$ and the degree of cross-linking $(\mathrm{C})$ expressed in percentage: $\mathrm{T}=$ $(\mathrm{a}+\mathrm{b}) \times 100 / \mathrm{V}[\%] ; \mathrm{C}=\mathrm{b} \times 100 / \mathrm{a}+\mathrm{b}$ [\%] ( $\mathrm{a}=$ mass of acrylamide in gramm; $\mathrm{b}=$ mass of cross-linker in gramm, $\mathrm{V}=$ volume in $\mathrm{mL}$ ). Lower $\% \mathrm{~T}$ is required for high-molecular weight proteins and a higher $\% \mathrm{~T}$ provides better resolution for low-molecular weight proteins. Gradient SDS-PAGE gels can provide a greater dynamic range of resolution (Westermeier and Naven 2002, Friedman et al. 2009). The scheme of the 2-DE is shown in Figure 2.

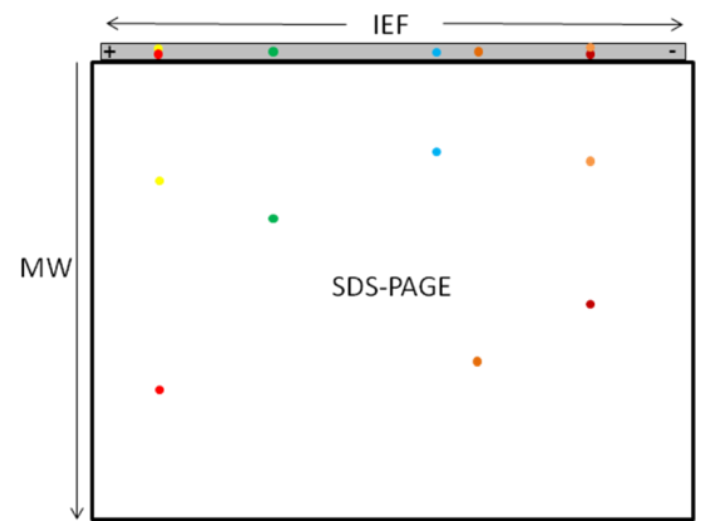

Figure 2. Orthogonal arrangement of the two separation steps in 2-DE. When the IEF is ready the IPG strips are equilibrated in a buffer containing SDS. Thus, the proteins are appropriate for separating them according to their $\mathrm{Mw}$ by SDS-PAGE. The IPG strips are put onto the top of the gel and the proteins start to migrate into the polyacrylamide gel. 


\subsubsection{Protein gel staining methods}

The choice of a staining method and a protocol depends on the required rigor of detection and quantification combined with available instrumentation, documentation capabilities and intended downstream analytical procedure (mass spectrometry, sequencing, enzyme-activity, Western blotting). Other consideration for staining methods include attributes of the sample, such as composition of protein of interest (presence or absence of a single amino acid) and availability of sample (protein concentration, protein distribution) (Miller et al. 2006, Steinberg 2009). The gel staining methods can be grouped as (1) postelectrophoresis and (2) pre-electrophoresis staining.

Most of the post-electrophoresis staining procedures include the following steps:

1. The gel is fixed to immobilize the proteins in the gel and to remove SDS, buffers or other interfering components.

2. The gel is stained with a colorimetric or fluorescent stain.

3. Quenching a staining reaction or destaining to reduce background.

Among the colorimetric stains the Coomassie Brilliant Blue (CBB) and silver nitrate protocols are most frequently used. Two modifications of CBB stain exist: CBB R-250 and G-250. CBB dyes bind to the proteins via electrostatic interaction with protonated basic amino acids (lysine, arginine and histidine) and by hydrophobic associations with aromatic residues. CBB stains are noncovalent and are reversible and do not interfere with subsequent MS analysis. CBB stains are generally treated as endpoint stains therefore they are useable for quantification with a limited dynamic range and sensitivity (Miller et al. 2006, Steinberg 2009). CBB G-250 stain is used for colloidal CBB staining procedure. Staining of protein on a clear background can be performed with phosphoric acid and CBB G-250. Recently, more than 600 different colloidal CBB staining protocols have been presented. Most of this protocols based on the same procedure published in 1985 and modified later in 1988 (Neuhoff et al. 1988). The most sensitive colloidal CBB staining protocol is called 'blue silver' method with a detection limit of $1 \mathrm{ng}$ for bovine serum albumin (Candiano et al. 2004).

Silver nitrate staining is widely used in proteomics due to its very good sensitivity $(<1$ ng). The staining technique is based upon saturating the gels with silver ions, washing the less tightly bound metal ions out of the matrix and reducing the protein-bound metal ions to form metallic silver. The first silver stain protocols were described in the early 1980s (Switzer et al. 1979, Oakley et al. 1980). Until recently, more than 100 silver staining protocols have been 
described. Despite its very good sensitivity the usage of silver stains have many limitations. In general, silver stains are published as a not endpoint procedure, therefore the staining intensity can vary from gel to gel. It shows only a narrow dynamic range thus silver staining is not reliable for quantification. In addition, the classical silver staining protocol with formaldehyde in the developer solution gives a much lower sequence coverage after MS protein identification in comparison with other stains, such as CBB or ruthenium bathophenantroline disulfonate (RuBPs) (Richert et al. 2004). However, there are modified protocols for acidic silver staining to make the procedure MS compatible (Shevchenko et al. 1996).

Until recently, numerous fluorescent post-electrophoresis dyes have been presented. In general, their sensitivity rivals silver staining and they provide a wide dynamic range for quantitative studies. The best fluorescent stains could detect subnanogram of proteins. However, the detection of fluorescent dyes requires specific instrumentation (laser scanner or CCD devices) and the commercialized stains are expensive. The most widely known fluorescent dyes are the SYPRO dyes developed by Molecular Probes. SYPRO Red and Orange dyes bind to the SDS-detergent coat of proteins in SDS-PAGE gels (Steinberg et al. 1996). While, SYPRO Ruby is a ruthenium metal chelate that binds to the basic amino acid proteins by a mechanism similar to colloidal CBB (Berggren et al. 2000). On the model of SYPRO Ruby, the synthesis and application of another ruthenium metal chelate dye, RuBPs has been published (Rabilloud et al. 2001). This procedure provides a much cheaper staining method, although the similarities/differences between RuBPs and SYPRO Ruby are controversial, as the commercially available SYPRO Ruby formulation has been improved (Miller et al. 2006). Besides these fluorescent dyes much more total protein gel stains are available from different vendors, such as Deep Purple, Flamingo, Oriole and LUCY.

In pre-electrophoresis staining the proteins are labelled with fluorescent dyes prior to electrophoresis. Two-dimensional difference gel-electrophoresis (2D-DIGE) was introduced in 1997 (Ünlü et al. 1997). It has strengthened the 2-DE platform by allowing detection and quantitation of differences between samples resolved on the same gel. The procedure is based on fluorescent cyanine dyes (CyDye) which have distinct excitation and emission spectra. Their charge and size are matched thus the same protein labelled with any of the CyDyes (Cy2, Cy3, Cy5) it will migrate to the same position within a gel. The differentially labelled samples are mixed prior to electrophoresis and resolved on the same gel (maximum three samples per gel in the case of 'minimal labelling'). After electrophoresis the differentially labelled samples are imaged separately then each of the image can be perfectly overlaid. 
There are two different cyanine-based protein labelling chemistries: (1) covalent labelling of lysine residues, also know as 'minimal labelling' and (2) covalent labelling of cysteine residues, also know as 'saturation CyDyes' (Miller et al. 2006, Wu 2006). There are three fluorophores ( $\mathrm{Cy} 2, \mathrm{Cy} 3$ and $\mathrm{Cy} 5)$ that can covalently bind to the $\varepsilon$-amino group of lysine forming an amide bond, where only a single lysine residue in each protein is labelled ('minimal labelling') (Tonge et al. 2001). The usage of Cy2-labelled internal standard (pooled sample) provides more accurate quantitative measurement between samples (Alban et al. 2003). Besides 'minimal labelling' stains, there are two other CyDyes (Cy3 and Cy5) that can covalently bind to the cysteine residues on proteins via a thioether linkage, where all accessible cysteine residues contained within a protein are labelled ('saturation labelling'). 'Saturation labelling' is very sensitive ( $5 \mu \mathrm{g}$ of total protein is enough), but in comparison with 'minimal labelling' or other post-electrophoresis stains the gel-image usually show altered spot pattern (Shaw et al. 2003).

\subsubsection{Image acquisition and analysis}

Image capture is the first step of image analysis. In general, there major devices can be used for image acquisition: (1) flatbed scanner, (2) charge coupled device (CCD) camera and (3) laser scanner (Miura 2001, Dowsey et al. 2010). Recently, CCD camera and laser scanner instruments are the most widely used, as they are appropriate for detecting fluorescent dyes. There are three major considerations that must be taken into account during image acquisition (Miller et al. 2006):

- Bit depth. This term describes the number of bits used to define each pixel of a digitized image and determines how many levels of gray can be generated. Thus, greater bit depth provides a greater range of grayscale to be presented by a pixel. For 2-DE image analysis 16-bit image file is required to be generated. This image stores $65536\left(2^{16}\right)$ gray values.

- Dynamic range. It is also called gray-level resolution that defines the actual range of grayscales that are utilized within a digital image.

- Resolution. It defines the number of pixels displayed per unit length of a digital image, often presented in dpi (dots per inch) or in micrometers (the size of the area each pixel represents). Images with higher resolution are composed of more pixels and have more image detail than those of lower resolution. 
The generated digital image can be further handled by image analysis software installed in a computer. The first generation of image analyses software were introduced in the early 1980s. For a long time image analysis software programs were not widely used due to the lack of an easy-to-use interface. The availability of low-cost personal computers, user-friendly graphical interfaces and powerful processors facilitated the development of the third generation software in the late 1990s (Appel et al. 1997). Recently used software packages can perform the image analysis in two different ways (Dowsey et al. 2010):

- Conventional analysis. Spot detection is performed prior to the alignment step. Commercial software packages are available, such as DeCyder (GE Helathcare), Dymension (Syngene) and PDQuest (BioRad).

- Image-based analysis. Image alignment is performed before consensus spot detection. Two commercial software packages are available: Delta2D (Decodon) and Progenesis SameSpots (Nonlinear Dynamics). These software packages are also called as fourth generation of 2-DE analysis software.

The emphasis on this fourth generation of analysis software has been on reducing the subjectivity of the image analysis. The fact that the alignment step is performed prior to the spot detection facilitates simultaneous spot detection on all gel images in an experiment and the resulting spot boundaries are identical on all gel images. The workflow is also called as 'SameSpots' approach (Silva et al. 2010). 'SameSpots' approach could reduce the total variance of a 2-DE experiment for post-stained gels but not for DIGE gels (Karp et al. 2008). The effect of post-electrophoretic gel-analysis on variance depends greatly on the type of the algorithms used in analysis software, including background subtraction and/or smoothing, spot detection, quantification, image warping, spot matching and normalization (Wheelock and Goto 2006). Several studies were performed to compare different software packages. All of these studies reveal remarkable differences in quantification of the same gels by different programs (Wheelock and Buckpitt 2005, Kang et al. 2009, Stessl et al. 2009).

\subsubsection{Experimental design and statistical analysis of a 2-DE study}

Appropriate experimental design and subsequent statistical analysis is mandatory to dependably extract all information that is generated in a 2-DE study. In an experimental design, the most important questions are how many and what type of replicates need to be made? Two types of replicates are reported in 2-DE studies: (1) technical replicates (repeated 
measurements of the same biological sample) and (2) biological replicates (different samples from the same treatment group). Thus, the different types of replicates are related to different sources of noise within a system. Technical variability can be introduced at the level of (a) sample collection, (b) sample preparation, (c) sample loading and electrophoresis and (d) staining and image analysis (Carpentier et al. 2008, Valledor and Jorrín 2011). While the biological variation is caused by factors like sex, age, genetic background and environmental factors (Winkler et al. 2008). The total variation observed between individuals within a group is the result of the technical and biological variation. The standard error (including biological and technical variation) for an experiment was described by Horgan (Horgan 2007). In this statistical study the author found that increasing the number of the biological replicates or technical replicates will reduce the standard error. However, increasing the number of biological replicates will produce a greater reduction than increasing the number of technical replicates. Thus, these data suggests that biological replication is always better than technical replication, especially when only a limited number of gels can be made due to budget or processing capacities of a laboratory. However, technical replicates are useable when the technical variability is still too high (Carpentier et al. 2008). In experiments when the number of possible replicates is limited (e.g. cost limitations), the sample yield is low, the biological variance is high or the interest lies not on the individual but rather on characteristics of the population (e.g. biomarker studies), an alternative to biological replicates is to use pooled samples (Karp et al. 2005). The magnitude of the biological variance greatly depends on the sample (Table 1.).

\begin{tabular}{|l|l|}
\hline Biological variances & $>5-20 \%$ \\
\hline cell culture & $>20-200 \%$ \\
\hline samples from inbreed mice & $>4-5$-fold \\
\hline human tissue vs. disease & $>2-20$-fold \\
\hline
\end{tabular}

Table 1. Biological variances in bioanalytical studies (Meyer and Stühler 2007).

In data analysis two approaches can be distinguished: exploratory data analysis (multivariate) and confirmatory data analysis (univariate). Univariate statistical methods examine the individual protein spots one by one, considering the different proteins as independent measurements. While exploratory data analysis approaches a biological problem from different point of view and tries to describe patterns, relationships, trends, outlying data, 
etc. The most commonly used univariate statistical methods are the parametric models such as Student's T-test (for comparing two groups) and ANOVA (for comparing more than two groups). Parametric univariate statistical tests are very powerful, but the data must respect the restrictive assumptions: continuous and normally distributed data, homogeneity of variance and independent samples (Carpentier et al. 2008). Logarithmic transformation of data is frequently used to improve the normality and homogeneity of variance (Gustafsson et al. 2004).

When two samples (e.g. control vs. treatment) are compared the most popular test is the Student's T-test which is a kind of hypothesis test. There are two statistical hypothesis involved in hypothesis testing. Null hypothesis $\left(\mathrm{H}_{0}\right)$ states that the means of the compared groups are the same whilst the alternative hypothesis $\left(\mathrm{H}_{1}\right)$ refers an existing difference between the means. In a 2-DE study rejecting the $\mathrm{H}_{0}$ means that the spot under test has been differentially expressed. The desired significance level $(\alpha)$ determines the decision as to which values go into the rejection region and be accepted as a significant difference. The test calculates a $p$-value which is the probability of incorrectly rejecting the $\mathrm{H}_{0}$. This probability is often referred to as the type I error rate. The significance level is typically fixed at 0.05 or 0.01 , which means that the test incorrectly rejects the $\mathrm{H}_{0} 5 \%$ or $1 \%$ of the time when it is in fact true. Conversely, the type II error is the error committed when a false $\mathrm{H}_{0}$ is not rejected. The probability of committing a type II error is designated by $\beta$. The statistical power (1- $\beta$ ) is the probability of correctly rejecting the $\mathrm{H}_{0}$ and not making type II error. Power is influenced by the variance (noise), the effect size, the number of replicates and the nominal significance. The target power is typically fixed at 0.8 (Daniel 2005, Hunt et al. 2005, Karp and Lilley 2007, Valledor and Jorrín 2011).

Power calculation is a useful statistical tool to calculate the required number of replicates to be able to detect a target effect size. In a 2-DE study power can be calculated for an experiment as a whole using an average noise or a value that encompasses $75 \%$ of the protein species (Lenth 2007, Karp et al. 2007). Various power calculation software programs are available. Piface software is a very useful free Java application for power calculation (Lenth 2007). In quantitative proteomics work, the differences of many separate proteins are routinely examined to test for significant differences between groups. Hundreds of comparisons lead to the multiple hypothesis testing problem: when many separate tests are performed many will be significant or false positive result by chance. A variety of statistical methods have devised to deal with this issue (Diz et al. 2010). The simplest and most 
formerly described method is the Bonferroni correction (Holm 1979). This method is very conservative and has low power to detect many true treatment differences. Therefore an alternative to the Bonferroni correction method was proposed by Benjamini and Hochberg (Benjamini and Hochberg 1995). This is the false discovery rate (FDR) which is the most frequently used method to control multiple hypothesis testing problem. With the BenjaminiHochberg method FDR can be controlled at different levels depending on the test stringency. An alternative to control FDR is calculating the FDR-adjusted probability ( $p$-value) (Reiner et al. 2003). An extension of FDR method was developed which is called positive false discovery rate (pFDR). The pFDR method cannot be controlled at specific levels as can FDR, but allows calculation of the $q$-value, which is analogous to FDR adjusted probability (Storey 2002, Storey 2003). Sequential goodness of fit (SGoF) was described recently as an alternative method to control multiple hypothesis testing problem. In general, SGoF has greater power than Bonferroni and FDR methods and a larger dataset results in more power in SGoF method (Carvajal-Rodríguez et al. 2009). The different statistical methods developed for controlling multiple hypothesis testing problem will give different cut off values for significance level. Therefore it is suggested to apply several different multiple testing methods to data in hand depending on the required statistical stringency of the experiment (more stringent biomarker discovery or more liberal pathway analysis) (Diz et al. 2010). Many of these methods can be performed simultaneously by using the free SGoF software (CarvajalRodríguez et al. 2009).

\subsubsection{Limitations and future prospects of $2-D E$}

Despite the numerous technical developments, 2-DE remains a very manual, subjective and labour-intensive process (Clark and Gutstein 2008). In addition proteins of extreme $\mathrm{Mw}$ and $\mathrm{p} I(10 \mathrm{kDa}>\mathrm{Mw}<200 \mathrm{kDa} ; 3>\mathrm{p} I<11)$, very hydrophobic proteins (e.g. integral membrane proteins) and low-abundance proteins are typically difficult to resolve or detect on 2D gels. Therefore complementary methods (MS-based techniques) are required to be able to obtain data from this portion of proteins (Garbis et al. 2005, Friedman et al. 2009). Despite its limitations, 2-DE is still the most frequently used method to analyse intact proteins with high resolution. In addition 2-DE is a powerful method to detect and quantify posttranslational modifications, alternative splicing and protein cleavage variants of proteins. Moreover the resolution of 2-DE can be improved by using narrow range IPG strips (e.g. pH 
5-6) and pre-fractionation methods. It is clearly visible that one of the key areas where 2-DE should deliver profit in the future will be the study of modification landscapes (Rabilloud et al. 2010).

\subsubsection{MS-based protein identification after 2-DE separation}

After 2-DE image analysis, the protein spots of interest should be identified. For characterisation and identification of proteins, MS is the method of choice. In general, the proteins are digested within the gel using various proteolytic enzymes, such as trypsin. Then, the peptide fragments are extracted from the gel and analysed by MS (Granvogl et al. 2007). For MS analysis, the peptide fragment molecules are converted into gas phase ions and subsequently they are analysed according to their mass : charge ratio $(\mathrm{m} / \mathrm{z})$. The introduction of soft ionisation mass spectrometry techniques in the late $80 \mathrm{~s}$, matrix assisted laser desorption ionisation (MALDI) and electrospray ionisation (ESI) revolutionised the protein identification in proteomics (Karas et al. 1987, Fenn et al. 1989). In combination with various mass analysers such as time of flight (TOF), quadrupole (Q), ion trap or hybrid analysers (e.g. Q-TOF), characterisation of fmol amounts of peptides or proteins is possible (Wilm et al. 1996). Peptide mass fingerprint (PMF) is a rapid and simple method for protein identification by MS analysis. The basis of the PMF is the molecular masses of peptide fragments detected in the mass spectra, serves as a fingerprint, which uniquely defines a particular protein. This fingerprint can be used to search the database of known sequences to find proteins with similar profiles (James et al. 1993). Often, however, information got from PMF measurement is insufficient for precise protein identification. Another approach uses raw tandem mass spectrometry data (MS/MS) for direct protein identification in databases. MS/MS measurement generates structural and sequence information by the fragmentation of an analyte ion of interest in the mass spectrometer. MS/MS sequence data-based algorithm was developed by Eng et al. and provides a very robust and facile approach to routine protein identification (Eng et al. 1994, Stone et al. 1998). Recently many search engines (e.g. Mascot, ProteinProspector) and databases (e.g. UniProt, International Protein Index) are available. 


\subsection{Neuroproteomics}

Advances in proteomic technologies have equipped the field of neuroproteomics to study the proteomes of the nervous system. Neuroproteomics can address the organisation of dynamic, functional protein networks and macromolecular structures. Therefore, it is contributing to the elucidation of neuronal disease mechanism and is a powerful tool for identification of biomarkers (Bayes and Grant 2009). The prevalence of some neurodegenerative diseases has increased in the last few decades, so neuroproteomic studies become more important and relevant. The analysis of the brain proteome(s) is the key for such an understanding, but at the same time, is a herculean task due to the fact that the brain proteome is one of the most complex and variable tissue proteome (Hamacher et al. 2008). In the last few decades numerous proteomic studies have been published related to various neurodegenerative disorders. In the next sections I will put a special emphasis on Alzheimer's disease (AD) and related proteomic studies.

\subsubsection{Cellular and neuropathological events of $A D$}

$\mathrm{AD}$ is the most common cause of dementia, accounting for $50-60 \%$ of all cases (Blennow et al. 2006). The brains of patients with $\mathrm{AD}$ can be histopathologically characterised by two lesions: (1) extracellular plaques composed of amyloid-beta (A $\beta$ ) peptide aggregates and (2) intraneuronal neurofibrillary tangles (NFT) of abnormally hyperphosphorylated tau protein, which is a neuronal microtubule- associated protein (Ittner and Götz 2011). A $\beta$ peptide is derived from its precursor protein, amyloid precursor protein (APP) by multiple protelolytic cleavages. Distinct aggregation forms of $\mathrm{A} \beta$ peptide are found in AD ranging from small oligomers to large fibrils (Irvine et al. 2008). Local inflammatory changes, neurofibrillay degeneration, neuritic/synaptic changes are associated with the early accumulation of $A \beta$ aggregates (Walsh and Selkoe 2004). By virtue its structure, $A \beta$ species are able to bind to a variety of biomolecules, including various plasma membrane receptor proteins of neuronal and glial plasma membrane. Through these interactions $A \beta$ could induce changes in numerous signalling pathways and subsequent cellular processes (Verdier et al. 2004). In addition a growing number of studies indicate that $\mathrm{A} \beta$ peptide aggregates can accumulate intraneuronally, which may play an important role in the pathogenesis of AD (LaFerla et al. 2007). Numerous research articles provide evidence for the involvement of 
mitochondrial dysfunction, endoplasmic reticulum (ER) stress, membrane disruption, oxidative stress, altered $\mathrm{Ca}^{2+}$ homeostasis, impaired synaptic transmission and axonal trafficking in A $\beta$-induced toxicity which lead to neuronal cell death (Pereira et al. 2005, Crouch et al. 2008, Demuro et al. 2010). According to the original 'amyloid cascade hypothesis', fibrillar $A \beta$ peptides of the amyloid plaques were thought to be responsible for the neurodegeneration of AD (Hardy and Higgins 1992). However, recently it is widely accepted that small $A \beta$ oligomers are the key contributors of $A \beta$-mediated neuronal cell death and synaptic dysfunction (Haass and Selkoe 2007). The main pathogenic events of AD are summarized in Figure 3.

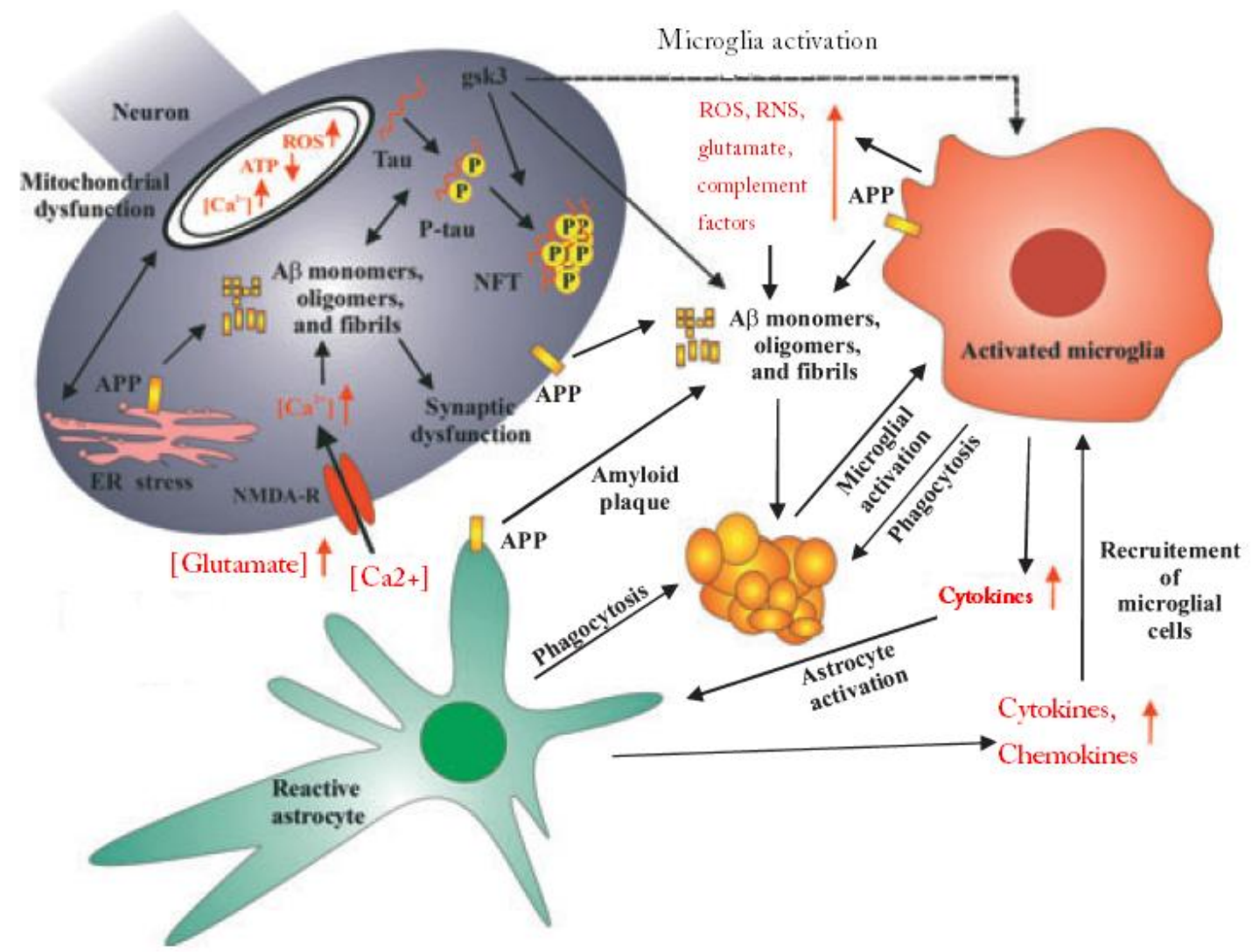

Figure 3. Schematic and simplified representation of the main pathogenic events occurring in AD brain. Glycogen synthase kinase-3 (GSK-3) plays a critical role in tau phosphorylation (Cho and Johnson 2004). Besides its role in tau phosphorylation, an increased GSK-3 activity is accompanied in AD pathology (Hernandez et al. 2009). Inflammatory processes and oxidative stress are also involved in AD pathological events (Mariani et al. 2005, Heneka and O'Banion 2007). Glutamate-mediated excitotoxicity is resulted from excessive activation of $\mathrm{N}$-methyl-D-aspartate receptors (NMDA-R), which mediates post-synaptic $\mathrm{Ca}^{2+}$ influx (Hynd et. al. 2004). Figure adopted from Korolainen et al. 2010. 


\subsubsection{Proteomics in $A D$ research}

Proteomics plays an undoubted role in understanding the molecular background of the patomechanism of AD. In the last few decades, there have been several attempts to study the proteome changes in AD using different approaches. Proteomic analysis of clinical samples is difficult due to the fact that it is rarely possible to obtain a biopsy, thus in general brain alterations can be examined only at autopsy. Autopsy samples usually represent the end-stage of AD. In addition proteomic data got from autopsy samples may be not relevant due to postmortem delay of sample preparation or co-morbidities, such as pneumonia. Thus, the possible reasons for inconsistent findings in different proteomic studies of $\mathrm{AD}$ are mainly related to interlaboratory variations in proteomic approaches and missing clinical data (Korolainen et al. 2010, Juhász et al. 2011).

Since the high-resolution 2-DE was introduced by O'Farrel in 1975 numerous 2-DE studies have been published in connection with $\mathrm{AD}$ research. The most complete summary of clinical proteomic studies in AD research was published in 2010 (Korolainen et al. 2010). In this review a detailed list of proteins (93 proteins) was published based on 43 2-DE proteomic studies in 13 different brain regions in mild cognitive impairment, early AD and AD patients published since 1999. The authors also made a meta-analysis using functional annotations can be found in gene ontology (GO) database. In the biological process category, oxidation/reduction related proteins represented the most significant group according to GO. This finding is in accordance with the fact that oxidative stress plays a role in the pathogenesis of AD (Pratico 2008, Ansari and Scheff 2010). In addition oxidatively modified proteins are associated with AD (Sultana et al. 2009). Besides oxidation/reduction, proteins related to glycolysis, anti-apoptosis, transport, metabolic process, protein folding and nervous system development also represented significant groups according to GO.

Cerebrospinal fluid (CSF) clinical samples are also studied intensely by different proteomic approaches. CSF is considered as a window into brain metabolism therefore proteins in CSF may often serve as indicators of neurodegenerative diseases and are rich source for biomarker discovery (Davidsson and Sjörgen 2006). In addition CSF can be collected quite easily and repeatedly, enabling examination of disease progression and the effect of drugs. In the same review published by Korolainen et al., a list of $25 \mathrm{CSF}$ proteins was published based on eight 2-DE studies. After meta-analysis, the authors found significant alterations in the CSF proteome can be linked to transport, complement activation and 
inflammatory response according to biological process category in GO database. These functional categories are in accordance with the fact that inflammatory processes are activated during $\mathrm{AD}$ pathogenesis (Heneka and O'Barion 2007). Despite the daunting analytical problems CSF is still widely investigated source of sample in AD research, especially in biomarker discovery (Maarouf et al. 2009). It has been described that a panel of protein changes may be perform better than any single biomarker. Therefore, a panel consists of 23 proteins were selected from 2-DE protein maps which could discriminate AD patients from non-AD participant (Finehout et al. 2007).

Due to the difficulties of clinical sample collection, animal models are essential in neuroproteomic studies, such as in AD research. Actually, seventy percent of all animals used in biomedical research are mice and rats. Over a thousand stocks and strains of mice have been developed, as have hundreds of mutant stocks that are used as models of human diseases (Nagy et al. 2007). Numerous transgenic and non-transgenic mice and rat models have been also developed to study the A $\beta$-related pathologies in AD. However, different models have different values and limitations with respect to pathogenic, therapeutic and functional understandings of AD (Philipson et al. 2010). Proteomics findings from animal models of AD were summarised excellently by Sowel et al. (Sowel et al. 2009). In this review article, a detailed list of proteins was published. Overlapping proteome changes of human AD brain samples and animal models of $\mathrm{AD}$ might be the most important indicators in $\mathrm{AD}$ progression. These proteins belong to five important functional groups: (1) cytoskeleton organisation; (2) energy production, metabolism; (3) redox homeostasis, antioxidant proteins; (4) chaperones and (5) synaptic integrity. Expressional and functional changes in these subsets of the brain proteome may lead dramatic and irreversible destruction of the action of nerve cells and subsequent neurotransmission (Juhász et al. 2011).

Besides animal models, various cell lines (e.g. SH-SY5Y human neuroblastoma) have been also developed to study the toxic effect of $A \beta$ peptide and to analyse the neuron-specific proteome changes (David et al. 2006, Joerchel et al. 2008). Human APP transfected SHSY5Y cells show alterations in mitochondrial respiratory functions and energy metabolism (Rhein et al. 2009). This finding is in accordance with clinical data which suggest that mitochondrial dysfunction is an early and important event in neuronal cell death during AD progression. Different aggregation forms of $A \beta 1-42$ peptide have a different effect of cellular vitality and induce different apoptotic pathways (Heinitz et al. 2006, Picone et al. 2009). These findings suggest that cell line models are useable in AD research and could provide 
useful information to understand the mechanism of $A \beta$-mediated neuronal cell death. However, the limitations of these model systems should be taken into account, as they are not fully proper for modelling a very complex human disease, such as AD.

\subsection{Aims}

Understanding and controlling the variance components in a 2-DE study are crucial. In neuroproteomics and $\mathrm{AD}$ research, one of the most frequently used model systems is mouse. Thus, a 2-DE analysis of mice brain proteome would be useful to estimate the magnitude of the variance components (technical and biological). Moreover, this study should reveal the quantitative limitations of this kind of experiments. Hence, I investigated the variation components of a 2-DE study analysing mice brain proteome.

In $\mathrm{AD}$ research, cell cultures are also frequently used model systems to investigate the molecular mechanism of the cellular events induced by different aggregation states of $A \beta 1-42$ peptide. The exact mechanism of cell death induced by oligomeric A $\beta 1-42$ is not elucidated, yet. Thus, a reliable 2-DE study would be useful to detect molecular changes after oligomeric A $\beta 1-42$ treatment using SH-SY5Y neuroblastoma cells. The functional classification of the identified proteins would be helpful to understand the mechanism of oligomeric A $\beta 1-42$ induced neuronal stress.

In the course of my Ph.D. work I attained the following aims:

1. Characterisation of the variation of mouse brain proteome by 2-DE:

1.1. The magnitudes of the biological- and technical variation were estimated.

1.2. Reproducibility, inter-assay studies were performed to characterise the quantitative limitations of a 2-DE study analysing mice brain proteome.

1.3. The effect of the genetic background on the total variation was investigated analysing mouse brain proteome by 2 -DE.

2. Proteomic study of the effect of oligomeric A $\beta 1-42$ in situ prepared from "iso- A $\beta 1-42$ ":

2.1. Significant protein expression changes were detected after oligomeric A $\beta 1-42$ treatment in SH-SY5Y neuroblastoma cells.

2.2. The identified proteins were sorted into functional groups to understand which subsets of cellular proteome play a role in oligomeric $A \beta 1-42$ induced cell stress. 


\section{Materials and methods}

\subsection{Chemicals}

Bathophenanthrolinedisulfonic acid disodium salt hydrate and potassium pentachlororuthenate(III) hydrate were procured from Alfa Aesar (Ward Hill, MA, USA). Tris, urea, thiourea, 3-(cyclohexylamino)-1-propanesulphonic acid (CHAPS), dithioerithriol (DTE), iodoacetamide (IAA), glycerol, retionic acid, phorbol ester, sodium ascorbate and dimethyl sulfoxide (DMSO) were obtained from Sigma-Aldrich (Budapest, Hungary). Sodium dodecyl sulfate (SDS) and piperazine diacrylamide were purchased from Bio-Rad (Hercules, CA, USA). Acrylamide and N,N'-methylenebisacrylamide were procured from GE Healthcare (Little Chalfont, UK). In the cell treatment study, oligomeric A $\beta 1-42$ was prepared in situ from "iso-A $\beta 1-42$ ". A $\beta 1-42$ has not only poor solubility, but its synthetic preparations also contain species with a wide range of aggregation grade, from oligomers to fibrils. To overcome the problems of $A \beta 1-42$ treatment, the neurotoxic peptide was prepared in situ from the precursor "iso-A $\beta 1-42$ " peptide. In the "iso-A $\beta 1-42$ " there is no amide bond between $\mathrm{Ser}^{26}$ and $\mathrm{Gly}^{25}$, but an ester bond formed by the hydroxyl side chain of $\mathrm{Ser}^{26}$ and the carboxyl group of $\mathrm{Gly}^{25}$. The incorporated ester bond decreases the propensity of the peptide to aggregate, thus the isopeptide "iso- $\mathrm{A} \beta 1-42$ " has enhanced water solubility. When the $\mathrm{pH}$ is raised to the physiological value, a fast $O \rightarrow N$ acyl-transfer reaction occurs resulting in native A $\beta 1-42$. The $O \rightarrow N$ acyl-shift can happen both in vitro and in vivo, thus "iso-A $\beta 1-42$ " can be used as a good precursor for A $\beta 1-42$ (Sohma et al. 2004). The synthesis of "iso-A $\beta 1-42$ " peptide was performed in our laboratory. The freshly prepared A $\beta 1-42$ from the precursor isopeptide contains mostly oligomers. The procedure of "iso-A $\beta 1-42$ " synthesis, the peptide conformation, aggregation processes and biological activity were discussed in details by Bozso et al. (2010). RuBPs stain was also synthesised in our laboratory, according to the procedure published by Rabilluod et al. (2001).

\subsection{Animals}

Two-month-old male NMRI or C3H/HEN mice (30-40 g) were housed and used under the approval of the Animal Care Committee at the University of Szeged. Housing conditions were standardised in accordance with the generally accepted parameters, such as constant 
room temperature $\left(22 \pm 2{ }^{\circ} \mathrm{C}\right)$, humidity level $(55 \pm 5 \%), 12 \mathrm{~h} \mathrm{light/dark} \mathrm{cycle,} \mathrm{food} \mathrm{and} \mathrm{water}$ available ad libitum.

\subsection{Cell culture and oligomeric A $\mathbf{A} 1-42$ treatment}

SH-SY5Y human neuroblastoma cells (Sigma-Aldrich) were grown for 10 days on 60 $\mathrm{mm}$ Petri dishes. Cell differentiation was initiated by the addition of $10 \mu \mathrm{M}$ retinoic acid and $16 \mathrm{nM}$ phorbol ester dissolved in a cell culture medium containing 0.5\% DMSO. On the first day, the number of non-differentiated cells in the wells was $2.5 \times 10^{5}$ cells $/ \mathrm{ml}$ in suspension. After 10 days of differentiation, the cells were bound as a monolayer to the plate, and cell counting gave a number of $3 \times 10^{5}$ cells $/ \mathrm{cm}^{2}$ (corresponding to $6.5 \times 10^{5}$ cells $/ \mathrm{ml}$ in suspension). The supernatant solution was removed using a pipette and a new medium (without fetal bovine serum), free from phenol red and differentiating agents such as retinoic acid, phorbol ester and DMSO, was added rapidly to each well (within $3 \mathrm{~s} /$ well) at room temperature. The cells were treated with freshly prepared, oligomeric $A \beta 1-42(15 \mu \mathrm{M})$ for $8 \mathrm{~h}$.

\subsection{Experimental details for the 2-DE analysis of mouse brain proteome}

2-DE brain proteome profiles of littermate or non-littermate NMRI mice were analysed. To calculate the technical variance, two randomly selected samples were used for running technical replicate gel sets $(n=4)$. In this study the same extraction of each sample was analysed on parallel gels. Thus, the technical variance includes all of the variance components that are derived from the 2-D gel-electrophoresis, staining, scanning and software analysis. To determine the total variance, seven series of biological replicate gels (four series of littermate and three series of non-littermate) were run using brain tissue taken from each mouse $(n=4)$. Hence the total variance includes the components of technical variance, sample preparation plus the variation of independently prepared mouse brain samples, the so-called biological variance. Five pairwise comparisons were performed to detect protein expression differences between mouse groups. Inter-experiments were made using littermate mice (experiment 1) or non-littermate mice (experiment 2) to estimate the run-to-run variance, when the animals were born and about two-months later sacrificed on the same day, and the sample preparation was performed in a short period of time. To analyse the potential protein expression differences between generations I compared the brain proteome profile of two 
consecutive generations of the same parentage (experiment 3). In this case, there was a twomonth difference between the two generations. A similar study was also made by comparing two non-littermate mice groups (experiment 4). In this comparison, there was about twomonth difference between the groups as well. Moreover, the brain proteome profiles of NMRI and $\mathrm{C} 3 \mathrm{H} / \mathrm{HEN}$ mice strains were compared (experiment 5). Altogether, this study includes eight groups of mice (four littermates, three non-littermates and one $\mathrm{C} 3 \mathrm{H} / \mathrm{HEN}$; four gels/group) plus two series of technical replicates, of the whole forty gels that were made and analysed.

\subsection{Sample preparation and 2-DE}

\subsubsection{2-DE analysis of mouse brain proteome}

The mice were sacrificed by decapitation, then the brains were dissected and the forebrains were divided into hemispheres. The right hemispheres were homogenised in a $5 \mathrm{x}$ volume 2-DE lysis buffer (7 M urea, $2 \mathrm{M}$ thiourea, 4\% CHAPS, $50 \mathrm{mM}$ DTE) supplemented with a $1 \%(\mathrm{v} / \mathrm{v})$ protease inhibitor cocktail (Sigma). The fresh homogenates were incubated on ice for $15 \mathrm{~min}$ then centrifuged at $14,000 \mathrm{~g}$ for $30 \mathrm{~min}$ at $4{ }^{\circ} \mathrm{C}$. The supernatants were pipetted into clean Eppendorf tubes. Brain lysates were purified with a 2-D Cleanup Kit (BioRad) according to the manufacture's instructions. After purification, the final protein pellets were resolved in a 2-DE lysis buffer $(100 \mu \mathrm{L} /$ sample). The protein concentration was determined by a Non-Interfering Protein Assay Kit (Calbiochem, Gibbstown, NJ, USA). A volume of samples containing $500 \mu \mathrm{g}$ of total protein was supplemented with a 2-DE lysis buffer (without protease inhibitor cocktail) to a total volume of $450 \mu \mathrm{L}$ plus $2.5 \mu \mathrm{L}$ Bio-Lyte 3-10 buffer (Bio-Rad) and left on $24 \mathrm{~cm}$, pH 3-10, NL IPG strips (Bio-Rad) for overnight rehydration. IEF was performed on an IEF cell (Bio-Rad) using a $24 \mathrm{~h}$ program for a total of $67,000 \mathrm{Vh}$. After IEF, the strips were equilibrated for $2 \times 10 \mathrm{~min}$ in an equilibration solution (6 $\mathrm{M}$ urea, $30 \%$ glycerol, $0.375 \mathrm{M}$ tris $\mathrm{pH} 8.8,5 \%$ SDS, trace bromphenol blue) supplemented with $20 \mathrm{mg} / \mathrm{mL}$ DTE. It was followed by a second equilibration for $2 \times 10 \mathrm{~min}$ with the same solution without DTE, but with $50 \mathrm{mg} / \mathrm{mL}$ IAA. After equilibration, the strips were applied to the second dimension to separate proteins in a polyacrylamide gel (10-14.5\% gradient polyacrylamide gel, $24 \times 20 \mathrm{~cm}$ ). The SDS-PAGE was performed at $50 \mathrm{~V}$ for $30 \mathrm{~min}$ and 90 $\mathrm{V}$ until the end of the run (Hoefer, Holliston, MA, USA). After SDS-PAGE, the gels were 
stained with RuBPs according to the protocol of Rabilloud et al. with modifications (all \% are in $\mathrm{v} / \mathrm{v})$ :

1. Fixation: at least $2 \times 30 \mathrm{~min}$ in fixation solution (10\% acetic acid, $30 \%$ ethanol in distilled water).

2. Staining: at least $6 \mathrm{~h}$ in staining solution (40\% acetic acid, $40 \%$ ethanol, $10 \%$ glycerol in distilled water plus $10 \mu \mathrm{L} / 100 \mathrm{~mL}$ of $20 \mathrm{mM}$ RuBPs stock solution).

3. Washing: 2 x $15 \mathrm{~min}$ in distilled water.

After staining, the gels were scanned on a FLA-5100 laser scanner (Fujifilm, Tokyo, Japan) using a $473 \mathrm{~nm}$ laser and the $575 \mathrm{~nm}$ lp filter at $100 \mu \mathrm{m}$ resolution, where the photomultiplier (PMT) was adjusted to $350 \mathrm{~V}$.

\subsubsection{Oligomeric AB1-42 treated SH-SY5Y cells}

Treated and untreated cells were washed three times with phosphate-buffered saline (PBS), then collected in $1.5 \mathrm{~mL}$ ice cold PBS. The suspensions were centrifuged at $1000 \mathrm{~g}$ for $10 \mathrm{~min}$ at $4^{\circ} \mathrm{C}$. The supernatants were removed and the cell pellets were stored at $-80^{\circ} \mathrm{C}$ until lysis. Each pellet was homogenised in $100 \mu \mathrm{L}$ 2-DE lysis buffer supplemented with a $1 \%$ $(\mathrm{v} / \mathrm{v})$ protease inhibitor cocktail. The fresh homogenates were incubated on ice for $15 \mathrm{~min}$ then they were lysed by sonication for 6 cycles (10 sec sonication/ $10 \mathrm{sec}$ break) on ice. The lysates were centrifuged at $14,000 \mathrm{~g}$ for $30 \mathrm{~min}$, at $4{ }^{\circ} \mathrm{C}$. The supernatants were then pipetted into clean Eppendorf tubes. Three samples per group were pooled to obtain a sufficient amount of protein for 2-DE (9 Petri-dishes/group, 3 gels/group). The protein concentrations were determined by a Non-Interfering Protein Assay Kit. A volume of samples containing $180 \mu \mathrm{g}$ of total protein was supplemented with a 2-DE lysis buffer to a total volume of 450 $\mu \mathrm{L}$ plus 2.5 $\mu \mathrm{L}$ Bio-Lyte 3-10 buffer and left on 24cm, pH 3-10, NL IPG strips for overnight rehydration. IEF was performed on an IEF cell using a $24 \mathrm{~h}$ program for a total of 75,000 $\mathrm{Vh}$. Equilibration, SDS-PAGE and gel staining were performed as described above in section 2.5.1. Following staining, the gels were scanned on a FLA-5100 laser scanner using a $473 \mathrm{~nm}$ laser and the $575 \mathrm{~nm} \mathrm{lp}$ filter at $100 \mu \mathrm{m}$ resolution, and the PMT was adjusted to $400 \mathrm{~V}$. 


\subsection{Image analysis}

Digitised 2-D gel images were analysed by Progenesis Samespots software version 3.3.3420.25059 (NonLinear Dynamics, Newcastle Upon Tyne, UK). To evaluate the technical and biological variation of NMRI mice brain proteome, all the technical and biological replicate gels were analysed together. Afterwards, the spots compared between gels had identical boundaries in all gels and a commonly defined spot-pattern was used for variance analysis (36 gels). To detect any significant differences, separate pairwise comparisons were made using littermate or non-littermate NMRI mouse groups. A similar pairwise analysis was performed to observe significant protein differences between NMRI and C3H/HEN mouse strains. A software-based analysis procedure was applied on the spots which were $100 \%$ matched across the gel sets in each comparison. For this reason the number of the analysed spots was different in each comparison.

In the case of cell treatment, gels were also analysed by Progenesis Samespots software and only the $100 \%$ matched spots were included in the software-based analysis.

\subsection{Statistical analysis}

\subsubsection{2-DE analysis of mouse brain proteome}

Following an image analysis, the normalised spot volumes were exported for subsequent statistical analysis. The variance component was characterised by the coefficient of variation $(\mathrm{CV} \%)$ that was defined as the ratio of the standard deviations of normalised spot volumes to the means, expressed in percentage terms. Using $\log _{10}$-transformed spot volumes, the standard deviation (SD) was also calculated for each group. The variations of each group were characterised by the median CV\% and the CV\% which encompassed $95 \%$ of the spots (95th percentile position). By making pairwise comparisons, different spots were identified. Each comparison was filtered to identify different spots having a FDR-corrected $p$-value $\leq$ 0.05 ; power $\geq 0.8$ and fold change $\geq 2.0$, as generally accepted significance levels. However the number of spots was also calculated which presented at least 1.5-fold change. Multiple testing statistical calculations (FDR-corrected $p$-value and SGoF) were performed by SGoF software. Using the non-transformed, normalised spot volumes, correlation coefficient $\left(\mathrm{R}^{2}\right)$ was also calculated to measure the group-to-group variation in each pairwise comparison. 
Piface software (version 1.73 - 22 December 2010) was used to calculate power for the variances of littermate and non-littermate biological replicates. To calculate power we followed the arguments published by Karp and Lilley in 2005, where the effect size = $\log _{10}($ fold change $)$, hence for 1.5 -fold change, the effect size $=0.176$ and for 2.0 -fold change, the effect size $=0.301$ (Karp and Lilley 2005).

\subsubsection{Oligomeric AB1-42 treated SH-SY5Y cells}

In 2-DE, the software-based analysis was filtered to detect different spots having a $p$ value $\leq 0.05$, power $\geq 80 \%$ and fold change $\geq 1.5$. The normalised spot volumes were exported from Progenesis SameSpots software to calculate the CV\%. The variations of each group were characterised by the median CV\%. Multiple testing statistical calculations (FDRcorrected $p$-value and SGoF) were performed by SGoF software. In the Western blot analysis, the differences between treated and untreated samples were determined by applying Student's T-test with a two-tailed distribution, performed by GraphPad Prism 5 software (GraphPad software, La Jolla, CA, USA). Here a $p$-value $\leq 0.05$ was considered statistically significant.

\subsection{Mass-spectrometric analysis and protein identification}

RuBPS stained gels were overstained with colloiddal Coomassie blue G-250 according to the "Silver Blue" staining protocol (Candiano et al. 2004). Individual spots of interest were excised from the gel, destained, and then subjected to in-gel digestion with trypsin for $18 \mathrm{~h}$ at $37{ }^{\circ} \mathrm{C}$ using modified protocol of Shevchenko et al. (1996). Tryptic peptides extracted from gel pieces using 50\% acetonitrile and 5\% formic acid were dried under a vacuum.

Digested protein samples were analysed on a Waters NanoAcquity UPLC system coupled with a Micromass Q-TOF premier mass spectrometer (Waters, Millford, MA, USA). 20 minlong gradient (3-40\%) of water and acetonitrile (both of them containing $0.1 \%$ formic acid) were applied on a Waters BEH130 C18 $75 \mu \mathrm{m}$ x $250 \mathrm{~mm}$ column $(1.7 \mu \mathrm{m}$ particle size with $130 \AA$ A pore size C18 packing). The mass spectrometer was operated in the DDA mode with lockmass correction, with a nominal mass accuracy of $3 \mathrm{ppm}$ for masses in the ideal intensity range. The most intense peptide was selected for fragmentation in a collision cell for $3 \mathrm{~s}$, for each MS scan. All the obtained data were processed and peaklists were generated by the Waters Proteinlynx Global Server, ver. 2.3 software using default settings. Each MS/MS 
sample was analysed using a Mascot 2.2.06 (Matrix Science, London, UK). The Mascot device was set up to search in Swissprot 57.12 database (2009.12.15 release, 513,877 entries) assuming the digestion enzyme trypsin. A database search was performed with a fragment ion mass tolerance of $0.15 \mathrm{Da}$ and a parent ion tolerance of $50 \mathrm{ppm}$ (6 ppm average mass error of validated hits, $95 \%$ below $20 \mathrm{ppm}$ ). An iodoacetamide derivative of cysteine was specified as a fixed modification in Mascot, while the oxidation of methionine was specified as a variable modification. In those cases when the same protein was found in multiple spots, error tolerant database searches were performed on the same dataset in order to identify modified residues or nonspecific cleavage products which may be responsible for shifted $\mathrm{p} I$ or Mw values. No other efforts were made to identify protein modifications, isoforms or alternative splicing products; the applied protocols were focused on identification of proteins.

Theoretical $\mathrm{p} I$ and $\mathrm{Mw}$ values of identified proteins were calculated using the Compute $\mathrm{pI} / \mathrm{Mw}$ tool at the Expasy website (http://www.expasy.org/tools/pi_tool.html). Values of the highest Mw processed (mature) form for each protein were selected.

Scaffold (version Scaffold_3_05_00, Proteome Software Inc., Portland, OR) was used to validate MS/MS based identifications of peptides and proteins. Protein identifications were accepted if they could be established at greater than $95.0 \%$ probability and contained at least 2 identified peptides. For multiple identifications, only the protein identified with the largest amount was listed in Table 4. and used for subsequent functional categorization. Protein quantity was estimated by the total number of MS/MS spectra assigned to the identified protein and average peptide ion intensity.

\subsection{Quantification of Hsp70 and EEF-2 by Western blot}

A volume of previously prepared samples containing $20 \mu \mathrm{g}$ of total protein was separated by $12 \%$ polyacrylamide gel $(6 \times 8 \mathrm{~cm})$ and transferred onto nitrocellulose membranes (Bio-Rad). After blocking in Tris-buffered saline (TBS) containing 5\% (m/v) bovine serum albumin (BSA), the membrane was incubated with first antibodies: anti-Hsp70 (Cell Signalling Technology, Danvers, MA, USA, 1:1000), anti-EEF-2 (Lifespan Biosciences, Seattle, WA, USA, 1:1000) and anti-beta-actin (Sigma-Aldrich, 1:1000) diluted in TBS containing $0.1 \%(\mathrm{v} / \mathrm{v})$ Tween-20 and 5\% BSA (TBST-BSA), then incubated with anti-rabbit or anti-mouse IgG (Dako, Glostrup, Denmark, 1:2500) also diluted in TBST-BSA as secondary antibodies. After incubation, immune complexes were detected with a chemo- 
luminescent substrate of peroxidase (Pierce, Rockford, IL, USA) according to the manufacturer's instructions by exposure to x-ray film (Sigma-Aldrich). The images were digitised on a FLA-5100 laser scanner using the digitising mode at $50 \mu \mathrm{m}$ resolution. The digitised images were analysed via Multigauge software (Fujifilm) and the band intensities were normalised using the band intensities of the beta-actin signal.

\section{Results}

\subsection{Characterisation of synthesised RuBPs stain}

In all 2-DE experiments demonstrated in this dissertation RuBPs stain was used for protein visualisation. As the similarities/differences between RuBPs and commercial Sypro Ruby are controversial, the detection limit and linear dynamic range of synthesised RuBPs stain were characterised. For this purpose, two-fold serial dilutions of a BSA standard were separated on $10 \%$ polyacrylamide gel and subsequently the protein band intensities were measured by MultiGauge image analysis program. After image acquisition it could be seen that RuBPs staining method could detect about 4-8 ng of BSA, where the protein bands were unequivocally distinguished from the background. RuBPs staining method has a good linearity in a wide range of protein amounts. The result reveals that RuBPs has a linear dynamic range for quantitation around three orders of magnitude (Figure 4/A and 4/B). For better comparison, the dynamic range of the commercially available Sypro Ruby dye was also presented in Figure 4/C. The dynamic range of synthesised RuBPs is fully comparable with commercial Sypro Ruby, although Sypro Ruby outperforms RuBPs in detection limit. According to the data can be found on the manufacturer's homepage, Sypro Ruby could detect subnanogram of proteins. However the prime cost of RuBPs is much lower than the price of Sypro Ruby. 
A,
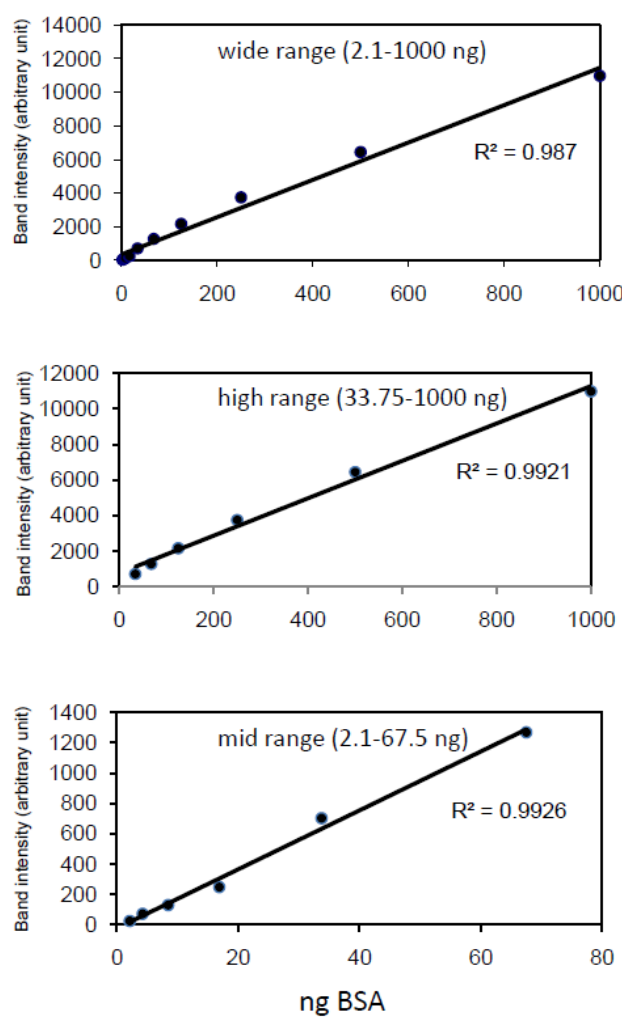

B,

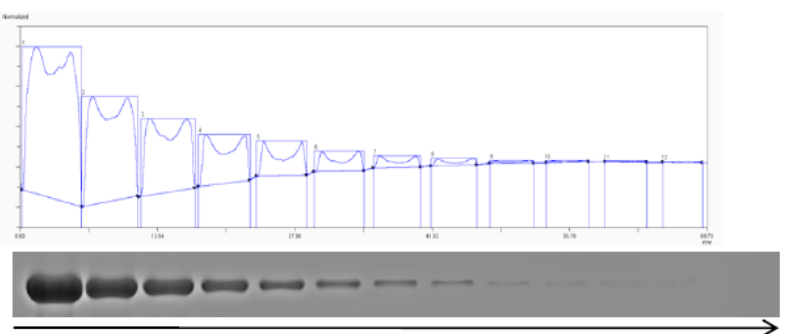

C, Two-fold serial dilution of BSA standard (4000-1 ng)

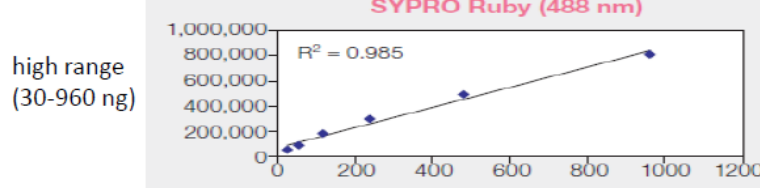

mid range

(2-60 ng)

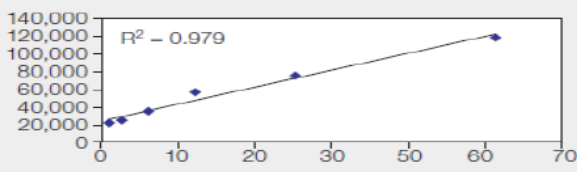

low range

(0.125-4 ng)

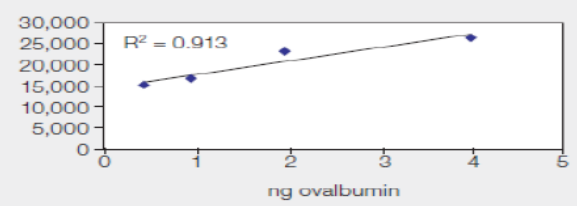

Figure 4. Characterisation of synthesised RuBPs stain. RuBPS staining method has a linear dynamic range for quantitation about three order of magnitudes (A) and could detect about 4$8 \mathrm{ng}$ of BSA (B). Detection limit and linear range of RuBPs are comparable with commercially available Sypro Ruby stain, data adopted from www.bio-rad.com (C). However, these results suggest that commercial stain outperforms RuBPs in detection limit, as Sypro Ruby could detect subnanogram of protein.

\subsection{2-DE analysis of mouse brain proteome}

\subsubsection{Technical and biological variations}

As the total variation is the sum of the technical and biological variation, it is expected that the total variance should be larger than the technical variance. The magnitude of the biological variance depends on the model system, genetic background and environmental factors. Genetic variation can have a huge impact on biological variance using non-isogenic populations like out-bred mouse stock. Presumably, the biological variance can be reduced by controlling the genetic origin. 
The technical variance of our 2-DE workflow was estimated by running technical replicate gels. In addition, using an out-bred mouse stock (NMRI), the effect of the genetic background was studied by comparing the biological variation of brain proteome of littermate (mice were collected from one litter) and non-littermate (mice were collected from different litters) mouse groups. From a separate analysis of each gel, around 1100-1200 spots could be detected, although the number of matched spots decreased when the number of gels in an analysis was increased. This is normal in 2-DE studies. In order to characterise the variance components, two series of technical-, four series of littermate biological- and three series of non-littermate biological-replicate gels (36 gels) were analysed together. The software analysis gave 446, 100\% matched spots across the gel set. Representative gel image is shown in Figure 5.

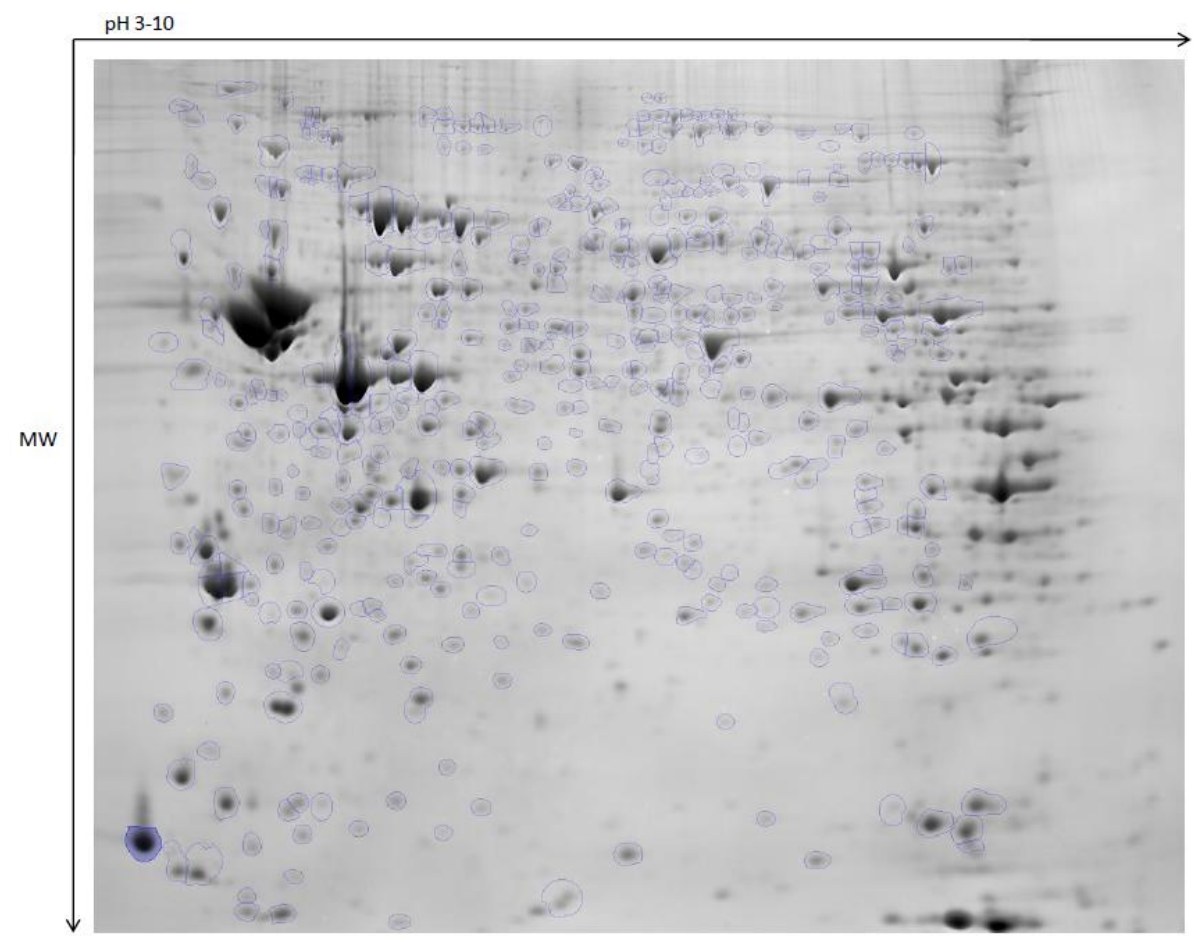

Figure 5. Representative 2-DE image. Outlined spots are matched across all gels (36) and used for variance calculation.

The variance components were characterised by $\mathrm{CV} \%$. The technical CV\% values of the two series of technical replicate gels were $9.4 \%$ and $9.1 \%$, respectively, with an average of 9.3\%. However, $95 \%$ of the spots had a CV\% below $21.1 \%$ and $19.9 \%$, with an average of $20.5 \%$. The normalised mean spot volumes of a technical replicate were plotted against the calculated technical variations $(\mathrm{CV} \%)$ of each spot to characterize the relationship between these two factors (Fig. 6/A). This figure indicates that the high volume spots have a lower $\mathrm{CV} \%$. The calculated total variances of littermate and non-littermate mouse groups were 
larger than the technical variance and it also displayed a small variation between the biological replicate groups. In littermate mouse groups the total variance $\mathrm{CV} \%$ values ranged from $9.6 \%$ to $13.1 \%$, with an average $12.1 \%$, and in non-littermate mouse groups the calculated CV\% values ranged from $10.8 \%$ to $11.4 \%$, with an average of $11.2 \%$. But CV\% values were $27.7 \% \pm 4.1$ at the 95 th percentile position in littermate mouse groups and $26.8 \pm$ 0.7 in non-littermate mouse groups. The distribution of CV\% values from technical and biological replicates revealed that the $\mathrm{CV} \%$ values were larger in littermate and non-littermate groups than in the technical replicates (Fig. 6/B). Analysing the variance values (CV\%) at the distribution level, the results suggest that the technical variance predominates in the total variance.

Sample size requirements were assessed by power calculation for typical fold changes in proteomic studies when the total variances (SD) encompassed $95 \%$ of the spots in littermate and non-littermate replicates (Fig. 7). When the significance level was set to 0.05 the power calculation indicated that to reach the target power of 0.8 , four replicates were required for a 2.0 -fold change and nine replicates for a 1.5 -fold change. The power calculation also indicated that the used sample size $(n=4)$ was appropriate to detect around 2.0-fold change in protein expression differences. Thus, in the subsequent pairwise comparisons the 2.0-fold or higher changes were used as one of the significance criteria, although the number of spots was also calculated which presented at least 1.5 -fold change difference in their expression level.

The proportion of biological variation in the total variation can be estimated by calculating the spot-by-spot $\mathrm{CV} \%$ difference between $\mathrm{CV} \%$ values of biological replicates (total variance) and technical replicates (technical variance). The majority of the analysed spots had larger CV\% values in littermate and non-littermate groups than in technical replicates $(76 \%$ of littermate spots and $67 \%$ of non-littermate spots). This also meant that around $25-30 \%$ of the spots had a negligible biological variation compared to the technical variation. The ratio of the biological variation compared to the total variation was determined by plotting the CV\% values against each other (Fig. 8). In this figure the spots below the $45^{\circ}$ line had a larger total variation than the technical variation. Analysing the spots which had a considerable (i.e. at least twice) biological variation compared to the technical variation, only a small fraction of spots could be found (18\% of littermate spots and $17 \%$ of non-littermate spots). These results also suggest that the technical variance has a big influence on the total variance. 

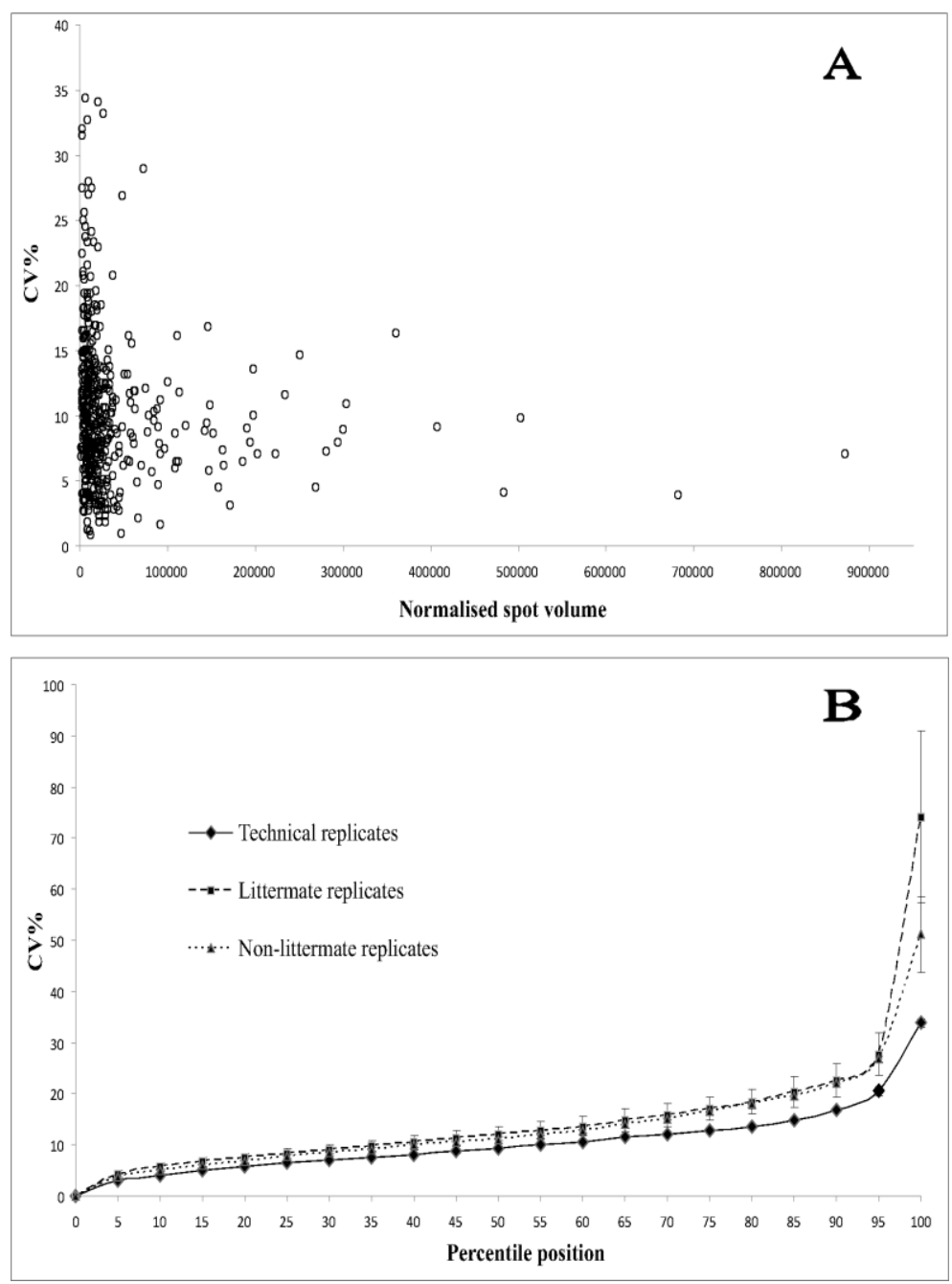

Figure 6. Relationship between technical variance (CV\%) and normalised mean spot volumes of a technical replicate (A). Distribution of CV\% values calculated from technical, littermate and non-littermate biological replicates $(\mathbf{B})$.
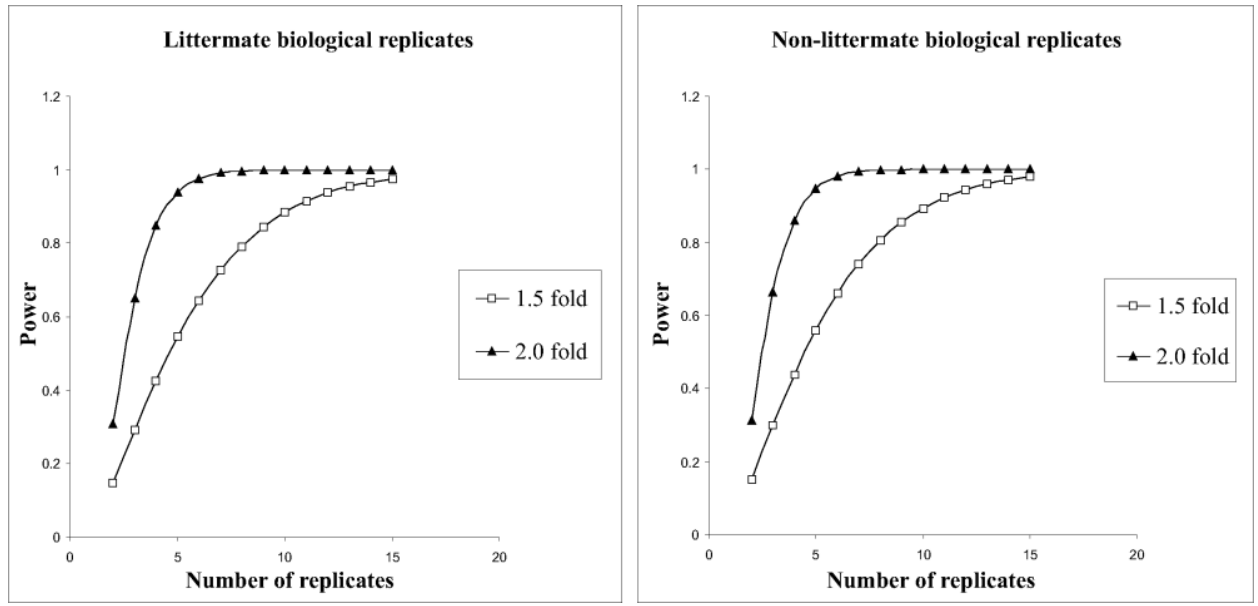

Figure 7. Power calculation in detecting various fold changes when the variance encompasses $95 \%$ of the spots. 


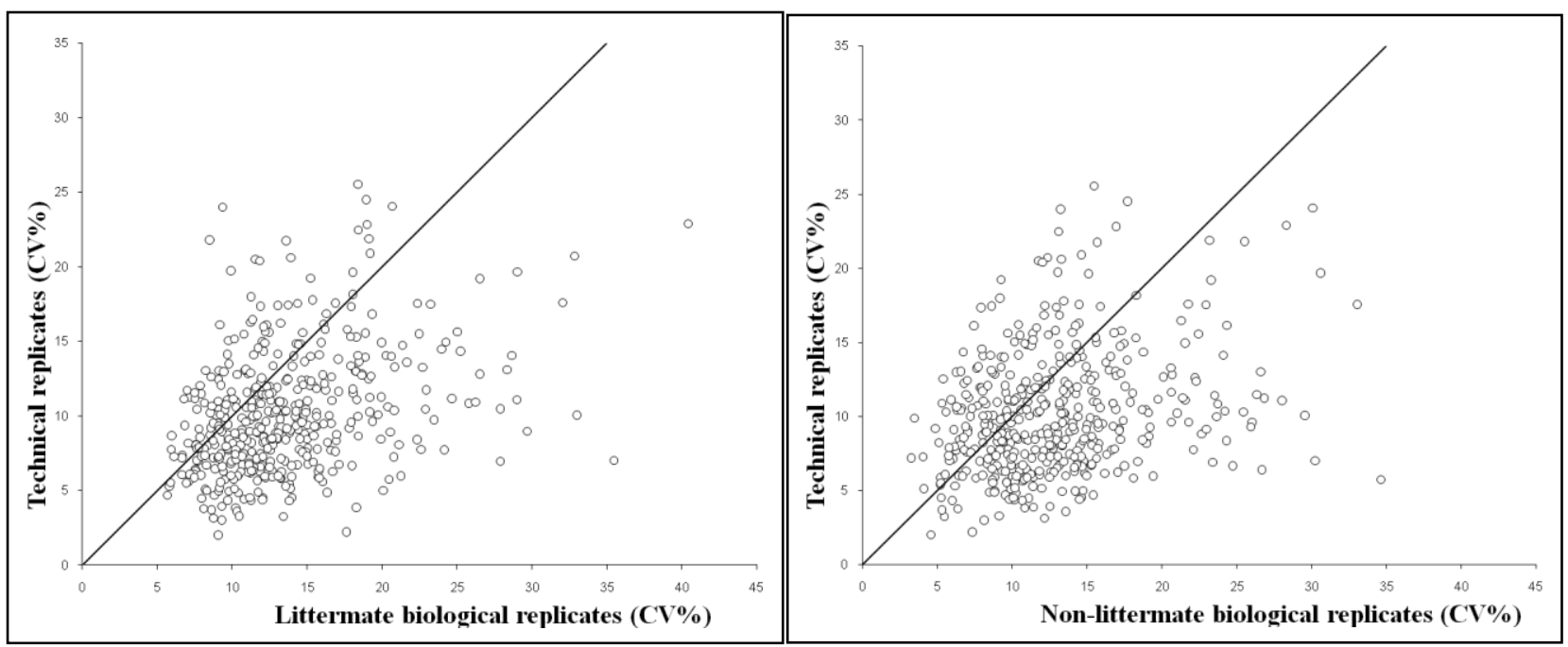

Figure 8. The technical and biological variation expressed in terms of the total variation. Calculated CV\% values of technical, littermate (left) and non-littermate (right) groups were plotted against each other.

\subsubsection{Detection of significant protein expression differences between NMRI mouse groups}

To avoid losing any potential protein expression differences, pairwise comparisons were made separately from the previously described analysis, which included all gels (36 gels). Inter-experiment reproducibility studies were performed using either littermate or nonlittermate mouse groups. In the littermate group, the mice were born in the same litter and about two-moths later they were sacrificed on the same day. The brain tissue samples were collected and then divided into two groups (4 brains/group). The tissue samples were processed in a short period of time and 2-DE was performed separately (4 gels/run). Based on our significance criteria, no protein expression differences could be found between the two groups. The same inter-experiment study was performed using non-littermate mice. In this study, the mice were born on the same day, but they were collected from different litters. The tissue processing and 2-DE were performed in the way described above for the littermate inter-experiment study. Similar to the previous study, no protein expression differences could be found.

To detect potential protein expression differences between generations, two consecutive generations of one litter were compared. Here, there was about two-month difference between the two generations. $1.9 \%$ of the matched spots were significantly different according to their FDR-corrected $p$-values. Analysing the fold changes, $0.2 \%$ of the spots had a larger fold change than \pm 2.0 . An analogous inter-experiment study was performed 
using non-littermate mice. One of the previously used non-littermate groups was compared to another non-littermate group, where there was about two-month difference between the birth dates as well. In this comparison $2.2 \%$ of matched spots were significantly different (FDRcorrected $p$-value) in their spot volume. Analysing the fold changes, no spots had a larger fold change than \pm 2.0 . In the previously used non-littermate group, almost the same CV\% (12.8\%) was obtained, independently of the analysis. Besides FDR, SGoF multiple test was also used to calculate adjusted $p$-values for each protein spot in all comparisons. According to the SGoF cut off value (0.05) more significant protein spots could be detected in every group. However, most of these spot did not present a remarkable difference, as they did not reach the \pm 2.0 -fold change. The biological variations of each group were characterised by the median CV\% values. Correlation coefficient analysis was also performed to measure group-to-group variation. The results of all pairwise comparisons were summarised according to their experiment number (see section 2.4) in Table 2.

\subsubsection{Comparison of NMRI mouse stock and C3H/HEN mouse strain}

One of the non-littermate NMRI mouse groups was compared to a non-littermate $\mathrm{C} 3 \mathrm{H} / \mathrm{HEN}$ mouse group as well. In this comparison, $15.5 \%$ of the matched spots were significantly different according to their FDR corrected $p$-values. The most striking differences could be seen between these two groups of mice, as $1.9 \%$ (FDR) or $2.4 \%$ (SGoF) of the spots had a larger fold change than \pm 2.0 , depending on the multiple test was used. The $\mathrm{CV} \%$ values were also very similar to the previously calculated values. The result of this comparison was also summarised in Table 2.

\subsection{Proteomic study of the effect of oligomeric Aß1-42 on SH-SY5Y cell line}

\subsubsection{2-DE and statistical analysis}

Differentiated SH-SY5Y human neuroblastoma cells were treated with freshly prepared oligomeric A $\beta 1-42$ for $8 \mathrm{~h}$. After treatment, cell lysates were separated by 2-DE. Although about 1000 spots could be detected on each gel, the software-based analysis of 2DE gel images focused on the spots that were $100 \%$ matched across all gels. In this way, the analysis gave 649 matched spots. Moreover, by using the SameSpots approach in the analysis, the spots compared between the gels had identical boundaries. 
Table 2. Summary of the pairwise comparisons made between NMRI and C3H/HEN biological replicates.

\begin{tabular}{|c|c|c|c|c|c|}
\hline & Experiment 1 & Experiment 2 & Experiment 3 & Experiment 4 & Experiment 5 \\
\hline Analysed spots $^{\mathrm{a}}$ & 782 & 733 & 830 & 689 & 593 \\
\hline CV\% value & $\begin{array}{l}\mathrm{CV} \%_{\mathrm{A}}=13.4 \\
\mathrm{CV} \%_{\mathrm{B}}=12.8 \\
\mathrm{CV} \%_{\mathrm{A}, \mathrm{B}}=14.4\end{array}$ & $\begin{array}{l}\mathrm{CV} \%_{\mathrm{A}}=13.1 \\
\mathrm{CV} \%_{\mathrm{B}}=12.8 \\
\mathrm{CV} \%_{\mathrm{A}, \mathrm{B}}=14.9\end{array}$ & $\begin{array}{l}\mathrm{CV} \%_{\mathrm{G} 1}=15.3 \\
\mathrm{CV} \%_{\mathrm{G} 2}=10.8\end{array}$ & $\begin{array}{l}\mathrm{CV} \%_{\mathrm{B}}=12.7 \\
\mathrm{CV} \%_{\mathrm{C}}=11.8\end{array}$ & $\begin{array}{l}\mathrm{CV} \%_{\mathrm{C}}=11.5 \\
\mathrm{CV} \%_{\mathrm{C} 3 \mathrm{H} / \mathrm{HEN}}=12.9\end{array}$ \\
\hline $\mathbf{R}^{2}$ value $^{\mathrm{b}}$ & 0.988 & 0.991 & 0.987 & 0.990 & 0.978 \\
\hline $\begin{array}{l}\text { FDR-corrected p-value } \\
<0.05\end{array}$ & 0 & 0 & $1.9 \%(16)$ & $2.2 \%(15)$ & $15.5 \%(92)$ \\
\hline SGoF $<0.05$ & $0.6 \%(5)$ & $5.5 \%(40)$ & $10.1 \%(84)$ & $16.1 \%(111)$ & $21.9 \%(130)$ \\
\hline $\begin{array}{l}\text { Fold change } \geq 1.5(\text { FDR } \\
<0.05)\end{array}$ & 0 & 0 & $0.96 \%(8)$ & $0.44 \%(3)$ & $8.6 \%(51)$ \\
\hline $\begin{array}{l}\text { Fold change } \geq 1.5 \\
(\text { SGoF }<0.05)\end{array}$ & $0.3 \%(2)$ & 0 & $3.4 \%(28)$ & $3.2 \%(22)$ & $11.3 \%(67)$ \\
\hline $\begin{array}{l}\text { Fold change } \geq 2.0(\text { FDR } \\
<0.05)\end{array}$ & 0 & 0 & $0.2 \%(2)$ & 0 & $1.9 \%(11)$ \\
\hline $\begin{array}{l}\text { Fold change } \geq 2.0 \\
(\text { SGoF }<0.05)\end{array}$ & 0 & 0 & $0.2 \%(2)$ & 0 & $2.4 \%(14)$ \\
\hline
\end{tabular}

${ }^{\mathrm{a}}$ Number of $100 \%$ matched spots across the gel set.

${ }^{\mathrm{b}}$ Result of the correlation coefficient analysis.

The total variations of untreated and treated group were characterised by calculating the median CV\%, as done in similar, published 2-DE studies. The median CV\% value was $11.8 \%$ in the untreated group and $15.7 \%$ in the treated group. Representative 2-DE gel images of the untreated group and treated group are shown in Figure 9.

According to the variation values, the power calculation reveals a detection limit around 2-fold change. Taking into account the significance criteria $(p \leq 0.05$ and power $\geq 0.8)$ and 2 -fold change, 14 spots could be detected ( 8 down- and 6 up-regulated). To avoid loosing any important protein expression changes occurred during the treatment, the minimal fold change criterion was expanded to 1.5 -fold change, where the original significance criteria were also true. According to these significance criteria, a software-based analysis revealed 52 significantly altered spots. Multiple test statistical approaches were also used to calculate the FDR- and SGoF-adjusted $p$-values (Table 3). The data can be found in this table reveal that only one spot is significantly different after FDR adjustment of $p$-values. However after SGoF 
analysis, all chosen spots can be accepted as significant difference between untreated and treated groups.
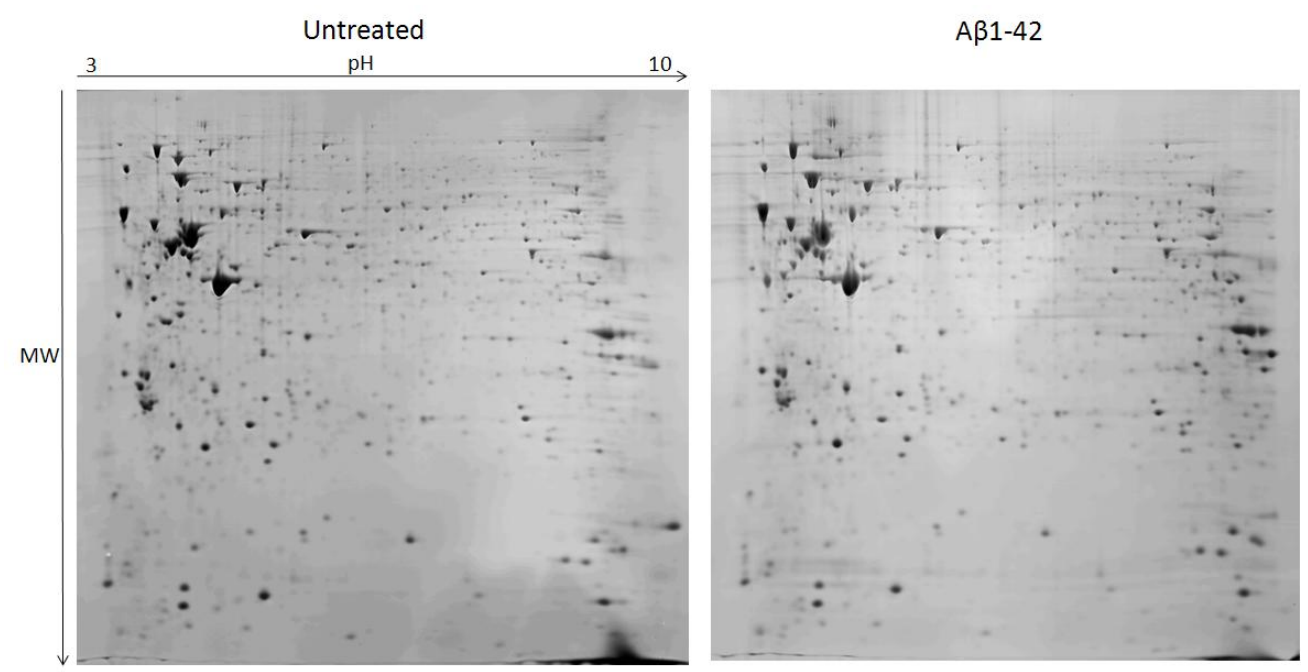

Figure 9. Representative gel images of untreated and A $\beta 1-42$ treated SH-SY5Y cell lysates.

\begin{tabular}{|c|c|c|c|c|}
\hline Spot & $p$-value & SGoF & FDR & \\
\hline 1 & 2.79E-05 & $2.13 \mathrm{E}-57$ & 0.0180973 & FDR $(0.05)$ \\
\hline 2 & 0.000229146 & $1.24 \mathrm{E}-56$ & 0.07435788 & \\
\hline 3 & 0.000467481 & $7.16 \mathrm{E}-56$ & 0.08344209 & \\
\hline 4 & 0.000717752 & $2.32 \mathrm{E}-54$ & 0.09316421 & \\
\hline 5 & 0.000914946 & $1.31 \mathrm{E}-53$ & 0.09896666 & \\
\hline 6 & 0.001795178 & $2.20 \mathrm{E}-51$ & 0.1056086 & \\
\hline 7 & 0.001873046 & $1.19 \mathrm{E}-50$ & 0.1056086 & \\
\hline 8 & 0.001890153 & $6.42 \mathrm{E}-50$ & 0.1056086 & \\
\hline 9 & 0.00235709 & $1.81 \mathrm{E}-48$ & 0.1056086 & \\
\hline 10 & 0.002466155 & $9.46 \mathrm{E}-48$ & 0.105686 & \\
\hline 11 & 0.002612441 & $4.91 \mathrm{E}-47$ & 0.105686 & \\
\hline 12 & 0.002768558 & $2.52 \mathrm{E}-46$ & 0.105686 & \\
\hline 13 & 0.0028251 & $1.29 \mathrm{E}-45$ & 0.105686 & \\
\hline 14 & 0.00358743 & $3.25 \mathrm{E}-44$ & 0.1081689 & \\
\hline 15 & 0.003681793 & $1.61 \mathrm{E}-43$ & 0.1081689 & \\
\hline $16-46$ & $\ldots$ & $\ldots$ & $\ldots$ & \\
\hline 47 & 0.0168206 & $1.90 \mathrm{E}-15$ & 0.1587104 & \\
\hline 48 & 0.01687367 & $5.49 \mathrm{E}-15$ & 0.1587104 & \\
\hline 49 & 0.01785121 & $1.57 \mathrm{E}-14$ & 0.1606696 & \\
\hline 50 & 0.01806337 & 4.40E-14 & 0.1606696 & \\
\hline 51 & 0.01826984 & $3.34 \mathrm{E}-13$ & 0.1606696 & \\
\hline 52 & 0.01885913 & $6.30 \mathrm{E}-12$ & 0.161047 & SGoF (0.05) \\
\hline
\end{tabular}

Table 3. Multiple test statistical analysis on those spots which were corresponded to the significance criteria ( $p$-value $<0.05$; power $>0.8$; fold change $\geq 1.5$ ). Spots were ordered increasingly according to their $p$-values calculated by Student's T-test. Therefore, these spots number are not identical with those can be found in Table 4 . 
After a mass spectrometric analysis, 47 proteins were identified (22 down- and 25 upregulated), as in some cases the same protein was identified from different spots (Table 4). For example, the eukaryotic elongation factor-2 protein (EEF2) was observed in three adjacent spots. Each spot displayed a significant difference and the relative fold changes ranged from -2.3 to -3.6 . Interestingly, heterogenous nuclear ribonucleoprotein K (hnRNP K) could be identified from two distant located spots with quite a big difference in their molecular weight. In addition, the higher molecular weight isoform of hnRNP K showed a 2.5-fold change decrease and the lower molecular weight isoform showed a 2.1-fold change increase at the expression level, which were clearly visible on the gel images (Fig. 10). The protein identification of hnRNP K protein had a high probability and in both spots the protein was identified with a lot of unique peptides (Fig. 10). Also, it should be mentioned that in the lower molecular weight spot only N-terminal peptides could be identified, which may account for the molecular weight difference. No differences in modification of peptides of the same protein from different spots could be significantly identified in case of neither proteins.

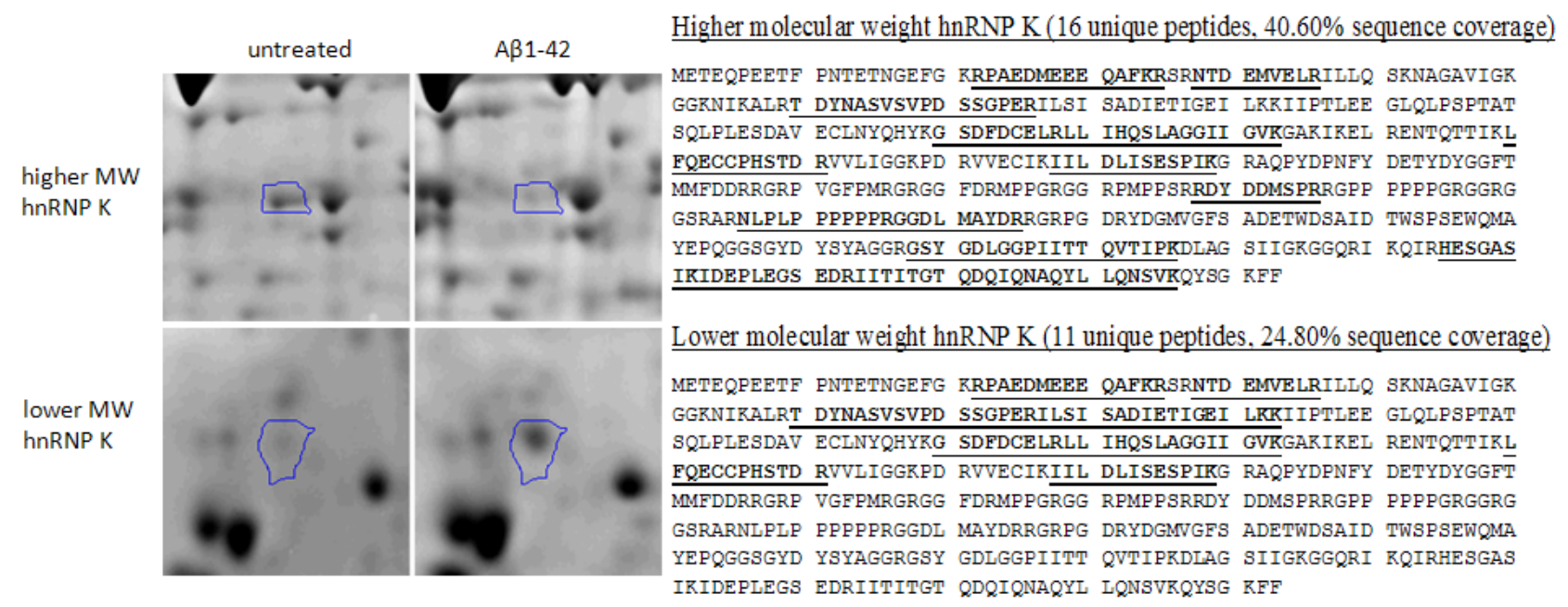

Figure 10. Altered protein expression of hnRNP K protein was found after A $\beta 1-42$ treatment. The amino acid sequence of hnRNP K protein is shown with one-letter amino acid codes. The bold, underlined sequence regions show the identified unique peptides obtained by mass spectrometry. 
Table 4. Proteins identified in SH-SY5Y cells treated with oligomeric A $\beta 1-42$.

\begin{tabular}{|c|c|c|c|c|c|c|c|c|c|}
\hline Spot & Protein name & 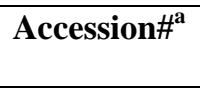 & $\mathbf{p I}^{\mathbf{b}}$ & Mw (kDa) ${ }^{b}$ & Peptides $^{\mathrm{c}}$ & Coverage $^{d}$ & $\begin{array}{c}\text { Fold } \\
\text { change }\end{array}$ & p-value ${ }^{e}$ & Function \\
\hline \multicolumn{10}{|c|}{ Down-regulated } \\
\hline 230 & Elongation factor 2 & P13639 & 6.42 & 95.18 & $19(19)$ & $25.90 \%$ & -3.6 & 0.00787 & Protein biosynthesis \\
\hline 1929 & $\begin{array}{l}\text { Heterogeneous nuclear } \\
\text { ribonucleoprotein } \mathrm{K}\end{array}$ & P61978 & 5.39 & 50.96 & $16(27)$ & $40.60 \%$ & -2.5 & 0.00416 & mRNA processing \\
\hline 219 & Elongation factor 2 & P13639 & 6.42 & 95.18 & $4(7)$ & $5.13 \%$ & -2.4 & 0.00987 & Protein biosynthesis \\
\hline 215 & Elongation factor 2 & P13639 & 6.42 & 95.18 & $2(2)$ & $2.68 \%$ & -2.3 & 0.00261 & Protein biosynthesis \\
\hline 264 & Glutaminyl-tRNA synthetase & P47897 & 6.74 & 87.67 & $12(21)$ & $17.80 \%$ & -2.1 & 0.00705 & Protein biosynthesis \\
\hline 465 & $\begin{array}{l}\text { ATP-dependent RNA helicase } \\
\text { DDX3X }\end{array}$ & O00571 & 6.73 & 73.11 & $13(15)$ & $22.20 \%$ & -2.1 & 0.0121 & mRNA processing \\
\hline 337 & Protein transport protein Sec23B & Q15437 & 6.23 & 83.44 & $9(13)$ & $19.00 \%$ & -2 & 0.00806 & $\begin{array}{l}\text { Intracellular protein transport (ER to } \\
\text { Golgi vesicle mediated transport) }\end{array}$ \\
\hline 396 & $\begin{array}{l}\text { Propionyl-CoA carboxylase alpha } \\
\text { chain, mitochondrial }\end{array}$ & P05165 & 6.16 & 74.25 & $12(28)$ & $23.30 \%$ & -2 & 0.00355 & Metabolic process (lipid metabolsim) \\
\hline 614 & $\begin{array}{l}\text { Asparaginyl-tRNA synthetase, } \\
\text { cytoplasmic }\end{array}$ & O43776 & 5.91 & 62.81 & $11(21)$ & $24.10 \%$ & -1.9 & 0.00485 & Protein biosynthesis \\
\hline 859 & Cytosolic non-specific dipeptidase & Q96KP4 & 5.66 & 52.75 & $17(27)$ & $49.90 \%$ & -1.9 & 0.00595 & Proteolysis \\
\hline 961 & $\begin{array}{l}\text { 6-phosphogluconate dehydrogenase, } \\
\text { decarboxylating }\end{array}$ & P52209 & 6.88 & 53.01 & $9(20)$ & $25.10 \%$ & -1.9 & 0.0118 & $\begin{array}{l}\text { Metabolic process (pentose } \\
\text { metabolism) }\end{array}$ \\
\hline 1896 & $\begin{array}{l}\text { Dihydropyrimidinase-related protein } \\
2\end{array}$ & Q16555 & 5.95 & 62.29 & $4(4)$ & $9.97 \%$ & -1.8 & 0.00373 & $\begin{array}{l}\text { Cytoskeleton organization (neuronal } \\
\text { growth) }\end{array}$ \\
\hline 328 & $\begin{array}{l}\text { Threonyl-tRNA synthetase, } \\
\text { cytoplasmic }\end{array}$ & P26639 & 6.23 & 83.44 & $8(16)$ & $12.60 \%$ & -1.7 & 0.0181 & Protein biosynthesis \\
\hline 759 & $\begin{array}{l}\text { Adenylyl cyclase-associated protein } \\
1\end{array}$ & Q01518 & 7.31 & 51.43 & $12(22)$ & $24.00 \%$ & -1.7 & 0.00283 & $\begin{array}{l}\text { Cytoskeleton organization (cAMP } \\
\text { pathway) }\end{array}$ \\
\hline 1705 & $\begin{array}{l}\text { 1,2-dihydroxy-3-keto-5- } \\
\text { methylthiopentene dioxygenase }\end{array}$ & Q9BV57 & 5.44 & 21.37 & $6(12)$ & $37.40 \%$ & -1.7 & 0.00247 & $\begin{array}{l}\text { Metabolic process (methyonine } \\
\text { biosynthetic process) }\end{array}$ \\
\hline 326 & $\begin{array}{l}\text { Far upstream element-binding } \\
\text { protein } 2\end{array}$ & Q92945 & 6.85 & 73.12 & $17(17)$ & $29.60 \%$ & -1.6 & 0.0189 & Regulation of transcription \\
\hline 517 & Phosphoglucomutase-2 & Q96G03 & 6.29 & 68.15 & $10(23)$ & $19.10 \%$ & -1.6 & 0.00604 & $\begin{array}{l}\text { Mebolic process (glucose metabolic } \\
\text { process) }\end{array}$ \\
\hline 659 & $\begin{array}{l}\text { Dihydropyrimidinase-related protein } \\
3\end{array}$ & Q14195 & 6.04 & 61.96 & $18(20)$ & $48.10 \%$ & -1.6 & 0.00187 & Cytoskeleton organization \\
\hline
\end{tabular}


Table 4. Continued

\begin{tabular}{|c|c|c|c|c|c|c|c|c|c|}
\hline Spot & Protein name & Accession\# $^{\mathrm{a}}$ & $\mathbf{p I ^ { \mathbf { b } }}$ & Mw (kDa) ${ }^{b}$ & Peptides $^{c}$ & Coverage $^{d}$ & $\begin{array}{c}\text { Fold } \\
\text { change }\end{array}$ & p-value ${ }^{e}$ & Function \\
\hline 1302 & $\begin{array}{l}\text { Pyruvate dehydrogenase E1 } \\
\text { component subunit beta, } \\
\text { mitochondrial }\end{array}$ & P11177 & 5.38 & 35.90 & $9(21)$ & $34.80 \%$ & -1.6 & 0.0158 & $\begin{array}{l}\text { Metabolic process (pyruvate metabolic } \\
\text { process) }\end{array}$ \\
\hline 1831 & Profilin-1 & P07737 & 8.47 & 14.92 & $9(9)$ & $63.60 \%$ & -1.6 & 0.000915 & Cytoskeleton organization \\
\hline 665 & $\begin{array}{l}\text { Tyrosyl-tRNA synthetase, } \\
\text { cytoplasmic }\end{array}$ & P54577 & 6.64 & 59.01 & $15(23)$ & $33.50 \%$ & -1.5 & 0.0179 & Protein biosynthesis \\
\hline 1119 & Poly(rC)-binding protein 2 & Q15366 & 6.33 & 38.22 & $8(15)$ & $23.00 \%$ & -1.5 & 0.016 & mRNA processing \\
\hline 1356 & $\begin{array}{l}\text { Phosphatidylinositol transfer protein } \\
\text { beta isoform }\end{array}$ & P48739 & 6.44 & 31.41 & $10(10)$ & $41.70 \%$ & -1.5 & 0.00622 & $\begin{array}{l}\text { Signal transduction } \\
\text { (phosphatidylinositol signaling } \\
\text { pathway) }\end{array}$ \\
\hline \multirow[t]{2}{*}{1624} & $\begin{array}{l}\text { Inosine triphosphate } \\
\text { pyrophosphatase }\end{array}$ & Q9BY32 & 5.51 & 21.31 & $4(4)$ & $33.00 \%$ & -1.5 & 0.0097 & $\begin{array}{l}\text { Metabolic process (nucleotide } \\
\text { metabolic process) }\end{array}$ \\
\hline & Up-regulated & & & & & & & & \\
\hline 508 & Heat shock $70 \mathrm{kDa}$ protein 6 & P17066 & 5.81 & 71.03 & $10(17)$ & $26.60 \%$ & 3.5 & 0.000229 & Stress response \\
\hline 82 & Hypoxia up-regulated protein 1 & Q9Y4L1 & 5.07 & 107.66 & $29(29)$ & $39.30 \%$ & 2.5 & 0.00417 & $\begin{array}{l}\text { Stress response (unfolded protein } \\
\text { response) }\end{array}$ \\
\hline 1359 & $\begin{array}{l}\text { Heterogeneous nuclear } \\
\text { ribonucleoprotein } \mathrm{K}\end{array}$ & P61978 & 5.39 & 50.96 & $11(20)$ & $24.80 \%$ & 2.1 & 0.00734 & mRNA processing \\
\hline 558 & Heat shock $70 \mathrm{kDa}$ protein 1 & P08107 & 5.48 & 69.92 & $23(25)$ & $43.50 \%$ & 2 & 0.00574 & Stress response \\
\hline 1501 & Cathepsin D & P07339 & 5.6 & 37.85 & $12(16)$ & $38.10 \%$ & 2 & 0.00839 & Proteolysis \\
\hline 1909 & $\begin{array}{l}\text { Ubiquitin carboxyl-terminal } \\
\text { hydrolase } 5\end{array}$ & P45974 & 4.91 & 95.66 & $19(27)$ & $29.30 \%$ & 2 & 0.0105 & $\begin{array}{l}\text { Proteolysis (ubiquitin-dependent } \\
\text { protein catabolic process) }\end{array}$ \\
\hline 77 & Hypoxia up-regulated protein 1 & Q9Y4L1 & 5.07 & 107.66 & $22(26)$ & $28.00 \%$ & 1.8 & 0.0168 & $\begin{array}{l}\text { Stress response (unfolded protein } \\
\text { response) }\end{array}$ \\
\hline 163 & Matrin-3 & P43243 & 5.87 & 94.49 & $11(14)$ & $15.80 \%$ & 1.8 & 0.0165 & Regulation of transcription \\
\hline 1012 & $\begin{array}{l}\text { Endoplasmic reticulum resident } \\
\text { protein ERp44 }\end{array}$ & Q9BS26 & 5.04 & 43.72 & $6(14)$ & $22.90 \%$ & 1.8 & 0.00484 & $\begin{array}{l}\text { Stress response (unfolded protein } \\
\text { response) }\end{array}$ \\
\hline 160 & Matrin-3 & P43243 & 5.87 & 94.49 & $8(10)$ & $11.70 \%$ & 1.7 & 0.00277 & Regulation of transcription \\
\hline 861 & Calreticulin & P27797 & 4.29 & 46.47 & $7(10)$ & $20.60 \%$ & 1.7 & 0.0018 & $\begin{array}{l}\text { Stress response (unfolded protein } \\
\text { response) }\end{array}$ \\
\hline
\end{tabular}


Table 4. Continued

\begin{tabular}{|c|c|c|c|c|c|c|c|c|c|}
\hline Spot & Protein name & 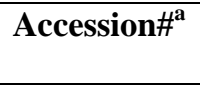 & $\mathbf{p I}^{\mathbf{b}}$ & Mw $(\mathbf{k D a})^{\mathbf{b}}$ & Peptides $^{c}$ & Coverage $^{d}$ & $\begin{array}{c}\text { Fold } \\
\text { change }\end{array}$ & p-value ${ }^{e}$ & Function \\
\hline 1633 & $\begin{array}{l}\text { ATP synthase subunit } \mathrm{d} \text {, } \\
\text { mitochondrial }\end{array}$ & O75947 & 5.22 & 18.36 & $12(14)$ & $65.20 \%$ & 1.7 & 0.000718 & Mitochondrial function \\
\hline 2008 & Glutathione S-transferase kappa 1 & Q9Y2Q3 & 8.53 & 25.37 & $9(19)$ & $46.90 \%$ & 1.7 & 0.0118 & $\begin{array}{l}\text { Stress response (cell redoxe } \\
\text { homeostasis) }\end{array}$ \\
\hline 580 & Lamin-B1 & P20700 & 5.11 & 65.96 & $31(31)$ & $46.40 \%$ & 1.6 & 0.0169 & $\begin{array}{l}\text { Nuclear protein (nuclear envelope } \\
\text { organization) }\end{array}$ \\
\hline 995 & Fumarate hydratase, mitochondrial & P07954 & 6.99 & 50.08 & $13(19)$ & $30.60 \%$ & 1.6 & 0.0126 & $\begin{array}{l}\text { Metabolic process (tricarboxylic acid } \\
\text { cycle) }\end{array}$ \\
\hline 606 & Lamin-A/C & P02545 & 6.44 & 72.22 & $17(21)$ & $28.90 \%$ & 1.5 & 0.00928 & $\begin{array}{l}\text { Nuclear protein (nuclear envelope } \\
\text { organization) }\end{array}$ \\
\hline 840 & Lysosomal Pro-X carboxypeptidase & P42785 & 6.21 & 51.04 & $8(29)$ & $15.10 \%$ & 1.5 & 0.00943 & Proteolysis \\
\hline 1138 & $78 \mathrm{kDa}$ glucose-regulated protein & P11021 & 5.01 & 70.47 & $16(23)$ & $26.60 \%$ & 1.5 & 0.00685 & $\begin{array}{l}\text { Stress response (unfolded protein } \\
\text { response) }\end{array}$ \\
\hline 1156 & SUMO-activating enzyme subunit 1 & Q9UBE0 & 5.17 & 38.45 & $11(18)$ & $38.70 \%$ & 1.5 & 0.0000279 & $\begin{array}{l}\text { Protein posttranlational modification } \\
\text { (protein sumoylation) }\end{array}$ \\
\hline 1287 & $\begin{array}{l}\text { Heterogeneous nuclear } \\
\text { ribonucleoprotein D-like }\end{array}$ & O14979 & 9.59 & 46.44 & $10(22)$ & $17.40 \%$ & 1.5 & 0.00189 & mRNA processing \\
\hline 1320 & Torsin-1A & O14656 & 6.17 & 35.78 & $11(20)$ & $38.90 \%$ & 1.5 & 0.00387 & Protein folding (molecular chaperone) \\
\hline 1404 & $\begin{array}{l}\text { Delta(3,5)-Delta(2,4)-dienoyl-CoA } \\
\text { isomerase, mitochondrial }\end{array}$ & Q13011 & 5.99 & 32.21 & $12(14)$ & $46.00 \%$ & 1.5 & 0.00236 & $\begin{array}{l}\text { Metabolic process (Fatty acid } \\
\text { metabolic process) }\end{array}$ \\
\hline 1491 & $\begin{array}{l}\text { Endoplasmic reticulum protein } \\
\text { ERp29 }\end{array}$ & P30040 & 6.08 & 25.85 & $11(26)$ & $37.90 \%$ & 1.5 & 0.0183 & $\begin{array}{l}\text { Stress response (unfolded protein } \\
\text { response) }\end{array}$ \\
\hline 1510 & Beta-hexosaminidase subunit beta & P07686 & 6.27 & 21.63 & $10(19)$ & $16.70 \%$ & 1.5 & 0.000467 & Lysosomal protein \\
\hline 1530 & Peroxiredoxin-4 & Q13162 & 5.54 & 26.57 & $9(14)$ & $49.80 \%$ & 1.5 & 0.00482 & Stress response (oxidative stress) \\
\hline 1594 & Cathepsin B & P07858 & 4.95 & 27.81 & $5(13)$ & $15.30 \%$ & 1.5 & 0.00886 & Proteolysis \\
\hline 1598 & Cathepsin B & P07858 & 4.95 & 27.81 & $7(24)$ & $25.40 \%$ & 1.5 & 0.00368 & Proteolysis \\
\hline 1906 & Citrate synthase, mitochondrial & O75390 & 7.39 & 49.01 & $15(27)$ & $30.70 \%$ & 1.5 & 0.00591 & $\begin{array}{l}\text { Metabolic process (tricarboxylic acid } \\
\text { cycle) }\end{array}$ \\
\hline
\end{tabular}

${ }^{\text {a }}$ Swiss-Prot/TrEMBLE accession number.

Theoretical molecular weight $(\mathrm{Mw})$ and isoelectric point $(\mathrm{pI})$ of the longest mature form of proteins (without signal peptides).

${ }^{\mathrm{c}}$ Number of unique peptides assigned to the identified protein (number of total peptides). For multiple identifications, only the protein identified with the largest amount was used in functional categorization.

${ }^{\mathrm{d}}$ Sequence coverage achived by MS analysis.

${ }^{\mathrm{e}}$ Significance level of Student's t-test (p-value $\leq 0.05$ was considerd statistically significant) 


\subsubsection{Classification of identified proteins}

The classification of the identified down- and up-regulated proteins gave well-defined functional groups (Fig 11). In the down-regulated protein group, six subgroups were found. Most proteins play a role in protein biosynthesis (28\%), metabolic processes $(22 \%)$, cytoskeleton organisation (18\%) and regulation of transcription/mRNA processing (18\%). The up-regulated protein group could also be divided into six subgroups, but these groups differed from the down-regulated ones. Most proteins are related to stress response (36\%), protein processes like proteolysis (24\%), metabolic processes (12\%) and regulation of transcription/mRNA processing (12\%). On the whole, it was clear from the proteins identified that the A $\beta 1-42$ influenced some of the main cellular functioning, such as protein biosynthesis, metabolic processes, cytoskeleton organisation and transcription. The high number of up-regulated stress proteins also reflects the cellular stress triggered by A $\beta 1-42$. What is more, most of the stress proteins have a chaperone molecular activity (seven proteins) and most of them belong to the ER chaperones and play role in ER stress.

\section{Down-regulated proteins}

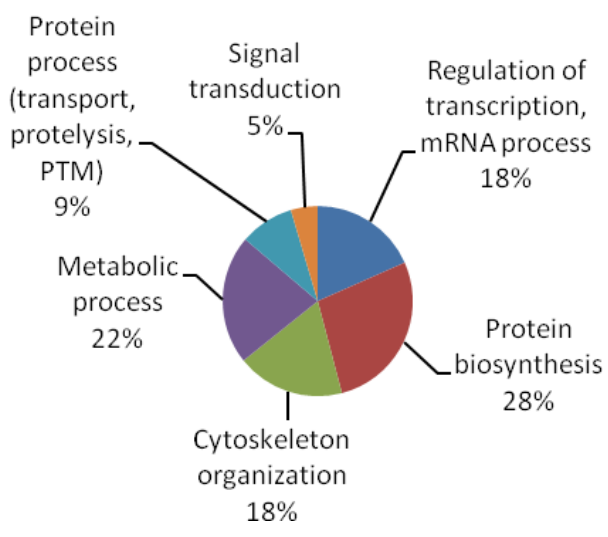

\section{Up-regulated proteins}

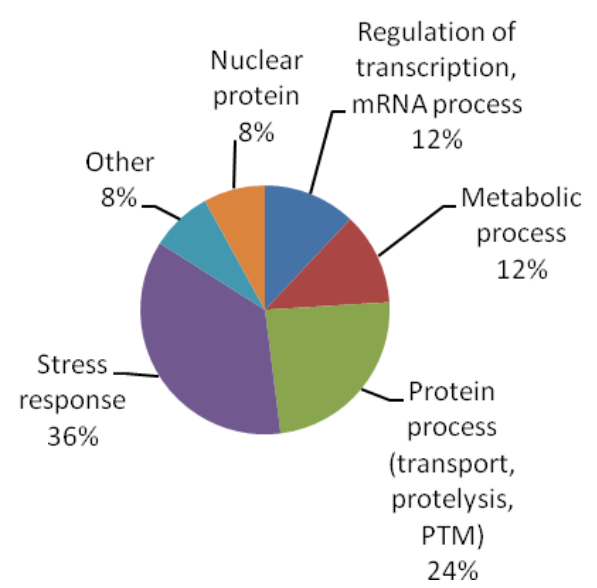

Figure 11. Functional classification down- and up-regulated proteins after $A \beta 1-42$ treatment.

\subsubsection{Validation of Hsp70 and EEF2 expression by Western blot analysis}

To confirm the results got from 2-DE, two of the most striking protein expression differences were chosen for Western blot validation (Fig. 12/A). Both of the validated 
proteins belonged to important protein subgroups that were influenced by oligomeric A $\beta 1-42$. In addition, Western blot validation also showed the importance of applying different multiple test statistical approaches. Both Hsp70 and EEF2 changes were not significant after FDR analysis although SGoF analysis found these changes significant. The Hsp70 band displayed a significant increase, and EEF2 displayed a significant decrease in their protein expression after analysing the band intensities normalised using the band intensities of the beta-actin signal (figures 12/B and 12/C).

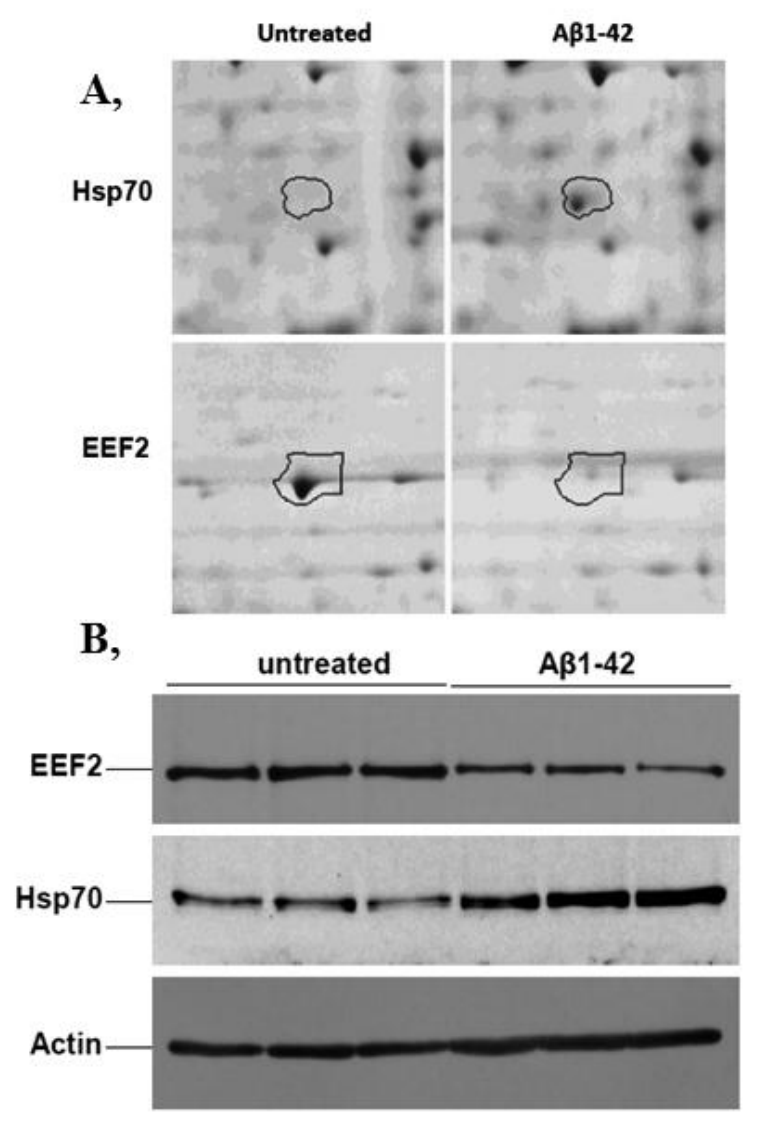

C, Hsp70

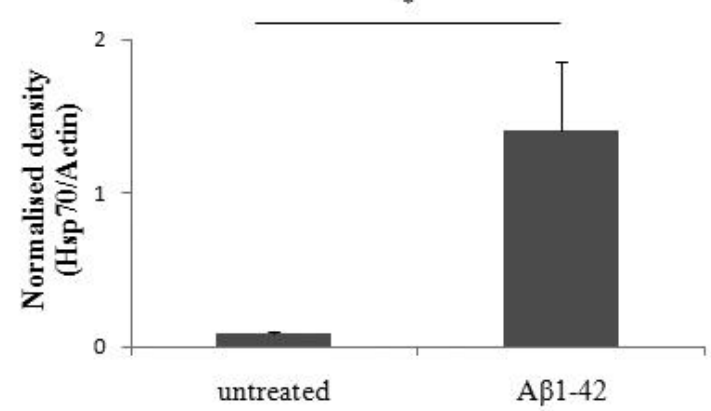

Figure 12. Expression profiles of Hsp70 and EEF2 obtained by 2-DE (A) and Western blot (B). Hsp70 showed a significant increase, whereas EEF2 showed a significant decrease in the protein expression profile analysis got by Western blot $(\mathbf{C})$. Here, data values are expressed as mean \pm SEM. ${ }^{*} \mathrm{p}<0.05,{ }^{* *} \mathrm{p}<0.01$. 


\section{Discussion}

\subsection{2-DE analysis of mouse brain proteome}

Experimental design and implementation play crucial role in quantitative proteomics, hence understanding and minimising the variables is essential in every experiment. The total variation is the sum of the technical and biological variation. The genetic background may have a huge impact on biological variation. Genetic factors determine the properties of the animals, including their sensitivities to different physical effects, chemical substances, pathogenic substances and microbes. In animal experiments, there are significant differences in the sensitivity between laboratory animal strains because of their differing genetic backgrounds. NMRI outbred mouse stock and C3H/HEN inbred mouse strain were used to perform 2-DE variance analysis. NMRI mice are used in many fields of research, such as pharmacology and toxicology, and are useful in behavioural and immunological studies (Moskophidis and Lehmann-Grube 1983, Lamberty and Gower 1992). Whereas, C3H/HEN mouse strain is mainly used for immunological studies, as they display a lower cellular immune response compared to other mouse strains (Steele et al. 1998). Not only the induction, but also the intensity of the reaction is influenced by genes. Consequently, the responses of the individuals of a genetically diverse population can differ both qualitatively and quantitatively. Reducing the genetic variability could be a practical way to decrease the biological variation. Thus, analysing for example a drug effect, smaller significant protein expression changes could be detected which may be masked by the higher biological variation. In present study, the effect of the genetic background on mouse brain proteome profile was investigated. Using standardised growth/housing conditions and 2-DE technical parameters, the brain proteome of littermate and non-littermate NMRI mice were analysed. Based on the first hypothesis, the genetic variability could be reduced by using littermate mice, which are born from the same parentage, so they may carry more homogenous genome. The total variation of 2-DE brain proteome profile of littermate or non-littermate NMRI and non-littermate $\mathrm{C} 3 \mathrm{H} / \mathrm{HEN}$ mice were estimated. Moreover, the technical variation of our 2-DE workflow was also assessed by running technical replicate gel sets. Using these data results, the proportion of technical variation in total variation was also calculated.

To determine the technical and total variation, two series of technical, four series of littermate biological and three series of non-littermate biological replicates were analysed together. In this way, the spots compared between gels had identical boundaries in all gels (36 
gels). The presented results are rather similar to those presented in previous papers. The technical variance displayed an average $9.3 \%$ median CV\% and the $95 \%$ of the spots had an average CV\% below 20.5\%. Other 2-DE studies reported an average 18-19\% (Hunt et al. 2005), 23\% (Molloy et al. 2003) and 16.2\% (Asirvatham et al. 2002) for the technical variance using similar post-electrophoresis staining methods, such as Sypro Ruby or Commassie Brillant Blue R-250. The calculated technical variance was also favourable when compared to another report made by DIGE method, where the median CV\% of the technical variation was around 5\% (Winkler et al. 2008). The median CV\% values of the total variation were on average $12.1 \%$ in littermate groups and $11.2 \%$ in non-littermate NMRI mouse groups. The total variation depends on the model system. A smaller variation may be presumed using a bacterial or cell culture than using mammalian or even human tissue samples. Previous 2-DE studies displayed average CV\% values of $31.2 \%$ for bacterial cultures, $26.0 \%$ for mammalian tissue cultures, $46.6 \%$ for mammalian primary cell cultures (Molloy et al. 2003) and 24.2\% in Medicago truncatula samples (Asirvatham et al. 2002). Other DIGE reports had median CV\% values of $18 \%$ in human platelet proteome (Winkler et al. 2008) and $19 \%$ in human liver samples (Zhang et al. 2006). In contrast with this, it has been published that the dependence of the variation on sample type was not significant analysing Wistar rat brain, liver and heart tissue and Erwinia carotovra bacterial samples by DIGE method (Karp and Lilley 2005).

Comparing the presented results to other similar studies (post-electrophoresis staining), a smaller technical variation can be seen. This may be due to the software analysis ("SameSpots") approach. It was reported that this approach leads to a significant reduction in SD compared to the traditional approach for Deep Purple stained 2-DE study using Erwinia carotovora culture (Karp et al. 2008). This research paper also suggests that the cost-benefit ratio of post-stains could be improved by analysing large changes of protein abundance. Whatever the case, software-based analysis plays a crucial role in quantitative 2-DE. The issue of quantitative 2-DE analysis was fully discussed in section 1.2.3.

The proportion of the biological variation in the total variation was estimated by calculating the SD difference between the total variation and the technical variation. The results show that using NMRI mice brain tissue samples the total variation is quite low, and in littermate and non-littermate groups the total variation was larger than the technical variation at the distribution level. The difference between the calculated technical variation and the total variation was quite low, so these values suggest that the technical variance predominates 
in the total variance. This analysis also revealed that about $70 \%$ of the spots had a larger total variation than the technical variation. Although just a small fraction of spots (17-18\%) had a dominant (at least double) biological variation compared to the technical variation, around 25$30 \%$ of the spots had a smaller biological variation than the technical variation. Very similar results were reported, where the authors also found a quite low total variation and a small proportion of biological variation in the total variation from analysing mouse brain tissue samples via the DIGE method (Karp et al. 2009). Comparing the CV\% values of the total variation in littermate or non-littermate NMRI mouse groups, a negligible difference was observed.

Inter-experiment studies were performed by making pairwise comparisons using either littermate or non-littermate NMRI mouse groups. The mice were sacrificed on the same day then the brain tissue samples were processed in a short period of time and 2-DE runs were performed separately ( 4 gels/run). No significant protein expression differences were found in the littermate and non-littermate groups analysing the data with either FDR or SGoF multiple test statistical approaches and taking into account the magnitude of minimal fold changes. When the gels of the littermate or non-littermate groups were treated as one group (8 gels/group), the median CV\% values were $14.4 \%$, and $14.9 \%$, respectively. Hence only a small difference was once again found between the total variations of littermate and nonlittermate mouse groups. Two generations of a littermate group, and two groups of nonlittermate mice were compared separately in order to detect any potential protein expression differences between consecutive mouse generations. It was assumed that more protein expression differences could be detected if we compared two groups of mice that had about two-month difference between their birth dates. Taking into account the magnitude of the relative fold change (1.5- or 2-fold change) and the significance criteria (FDR-corrected $p$ value $\leq 0.05$ and power $\geq 0.8$ ), our analysis revealed that less than $1 \%$ of the matched spots were significantly different. However, after SGoF analysis more, significantly different protein spots could be detected. Analysing the relative fold changes, the data revealed that no or only a few spots displayed 2-fold or higher differences in their expression level. Different results could be obtained depending on the multiple tests statistical approaches. The issue of statistical analysis of a 2-DE dataset was fully discussed in section 1.2.4.

A pairwise comparison was also performed using one of the non-littermate NMRI groups and one group of non-littermate $\mathrm{C} 3 \mathrm{H} / \mathrm{HEN}$ mice. NMRI is an out-bred mouse stock, while $\mathrm{C} 3 \mathrm{H} / \mathrm{HEN}$ is an inbred mouse strain. Our analysis also found a very similar and a quite 
low total variance, but the highest number of significant protein expression differences was observed in this comparison.

\subsection{Proteomic study of the effect of oligomeric Aß1-42 on SH-SY5Y cell line}

Proteomic approaches like 2-DE allow one to simultaneously study the expression levels and posttranslational modifications of hundreds of proteins. Hence researchers can get better information about the physiological state of a cell, tissue or an organ under non-normal physiological conditions at the protein level. Several proteomics studies have already been published in AD investigations. Despite the accumulated knowledge, the exact mechanism of $A \beta 1-42$ induced neurodegeneration remains unclear. Recently, investigations of oligomeric $\mathrm{A} \beta$ induced neurodegeneration have come to the fore, as it is now widely accepted that $\mathrm{A} \beta$ toxicity is positively linked to $A \beta$ oligomers. In addition, oligomers and fibrillar aggregates of A $\beta 1-42$ have a different effect on cellular vitality and induce different apoptotic pathways (Heinitz et al. 2006, Picone et al. 2009).

The toxic effect of A $\beta 1-42$ on differentiated SH-SY5Y cells was published earlier (Datki et al. 2003). Cell lines are good and useful models in proteomics for investigating A $\beta 1$ 42 induced neurodegeneration. P301L tau expressing SH-SY5Y cells revealed that a significant fraction of proteins altered after fibrillar $A \beta 1-42$ treatment (David et al. 2006). The treatment of cholinergic SN56 cells by oligomeric A $\beta 1-42$ also displayed alterations in the expression and phosphorylation levels of a number of proteins (Joerchel et al. 2008). To demonstrate the reproducibility and reliability of our 2-DE workflow, normalised spot volumes were used to calculate the median CV\% for each group. The CV\% value was $11.8 \%$ in the untreated group and $15.7 \%$ in the treated group. The calculated total variation values were favourable when compared with the results of a previous paper, where the total variance was around $26 \%$ using a similar mammalian tissue cell culture and post-electrophoresis staining like Sypro Ruby (Molloy et al. 2003). The presented 2-DE results revealed numerous, significant protein expression changes (22 proteins down- regulated and 25 proteins upregulated). The image analysis generated data were analysed thoroughly by different multiple test statistical approaches (FDR and SGoF). In addition, to verify the 2-DE results two of the most strikingly altered proteins were confirmed by Western blot. After a functional classification of the identified proteins, it was apparent which cellular processes were influenced by oligomeric A $\beta 1-42$. Also, many down-regulated proteins play a role in 
cytoskeleton organisation. Dihydropyrimidinase-related protein-2 (DRP-2) displayed the biggest decrease of the cytoskeleton organisation related proteins. Here, DRP-2 plays a role in axon guidance and neuronal growth (Inagaki et al. 2001), and the decreased protein expression level of DRP-2 was mentioned in many AD proteomic studies (Schonberger et al. 2001, Tsuji et al. 2002, Sultana et al. 2007). A number of the identified proteins play a role in metabolic processes related to carbohydrate, nucleotide and lipid metabolism. In this experiment, a significant decrease in the pyruvate dehydrogenase E1 component subunit beta (PDHE1-B) was found. PDHE1-B is a subunit of pyruvate dehydogenase (PDH) complex. PDH catalyses the conversion of pyruvate to acetyl-CoA that enters the tricarboxylic acid cycle (TCA), which is the first step of oxygen-dependent energy production that occurs in mitochondria (Pithukpakorn 2005). A decreased PDH protein level and activity was described in 3xTg-AD mice as early as 3 months of age (Yao et al. 2009). Besides PDHE1-B, I found changes in the protein expression of two other TCA enzymes (fumarate hydratase and citrate synthase), one glycolytic enzyme (phosphoglucomutase 2) and one subunit of ATP synthase complex V (ATP synthase subunit d), which may suggest the altered functioning of TCA and energy production. Alterations in TCA and related mitochondrial abnormalities were published in papers that analysed human brain samples taken from patients with autopsyconfirmed $\mathrm{AD}$ and clinical dementia ratings before death (Bubber et al. 2005). Mitochondrial respiratory functions and energy metabolism also showed alterations when compared with control and human APP transfected SH-SY5Y cells (Rhein et al. 2009). Analysing the upregulated proteins, most of them are found to have a stress-related function. Moreover, most of these proteins have a molecular chaperone activity. Molecular chaperons and heat shock proteins are critical regulators of proteins associated with neurodegenerative diseases like AD (Koren et al. 2009). In this study, two forms of heat shock $70 \mathrm{kDa}$ protein (Hsp70) were identified with a significantly increased protein expression level. In addition, our 2-DE results were confirmed via Western blot using an anti-Hsp70 antibody, which detected the endogenous level of total Hsp70. The increased expression level of Hsp70 was mentioned in many studies related to $\mathrm{AD}$ and also $\mathrm{A} \beta 1-42$ toxicity research that analysed either human samples or cell cultures (Di Domenico et al. 2010, Di Carlo et al. 2010). Besides Hsp70, six more proteins were identified as molecular chaperones. Interestingly, all of them have been described as members of endoplasmic reticulum chaperones and some of them play a role in unfolded protein response (UPR) (Anelli et al. 2002, Meunier et al. 2002, Ma \& Hendershot 2004). UPR is an evolutionary conversed cell stress response, which initially seeks to 
compensate for the damage, but can eventually trigger cell death if ER dysfunction is severe or prolonged (Xu et al. 2005). A $\beta 1-42$ induced UPR was in an aggregation state-dependent manner, where the oligomeric A $\beta 1-42$ was more toxic to cells primed for UPR (Chafekar et al. 2007). Moreover, fibrillar A $\beta 1-42$ induced UPR was also demonstrated (Lee do et al. 2010). Most of the down-regulated proteins in fact play a role in protein biosynthesis. Within this group of proteins the EEF-2 displayed the most striking decrease. To verify the results got from 2-DE, the protein expression level of EEF-2 was confirmed by a Western blot analysis. In addition, a significantly decreased expression level of total EEF-2 was seen by comparing postmortem AD brains to controls ( $\mathrm{Li}$ et al. 2005). The protein expression of hnRNP $\mathrm{K}$ has to be described separately, as it may be identified from two distinctly located spots with quite a big difference in their molecular weight. Moreover, the higher molecular weight $(\sim 50 \mathrm{kDa})$ form showed a significant decrease and the lower molecular weight ( $30 \mathrm{kDa}$ ) form displayed a significant increase at the expression level. hnRNP $\mathrm{K}$ is a $50-52 \mathrm{kDa}$ protein that is a component of the heterogeneous nuclear ribonucleoprotein (hnRNP) complex, but also can be found in the cytoplasm and mitochondria and it has been implicated in chromatin remodeling, transcription, splicing and translation (Bomsztyk et al. 2004). Four isoforms of hnRNP K were described in a very recent article (Kimura et al. 2010). Here, in this study the original form $(50-52 \mathrm{kDa})$ was decreased and the unspecified lower molecular weight form $(30 \mathrm{kDa})$ was increased. For both forms, the expression changes were relatively high and a mass spectrometric analysis provided a firm identification. The increase of the lower molecular weight form may indicate the presence of a new isoform or an elevated proteolytic process of hnRNP K. It has been reported that hnRNP $\mathrm{K}$ interacts and is proteolysed by calpain (Kimura et al. 2003). In addition, the inactivation of hnRNP K induces apoptosis (White et al. 2010).

\section{Summary}

In this section, I would like to summarize the results got from my experiments.

First, the small values for the technical variation and total variation obtained from the presented 2-DE experiments (mouse brain and SH-SY5Y cell line proteome studies) indicate that the parameters of the 2-DE workflow are well standardised. The calculated variability 
results were favourable when compared with previously published studies. "SameSpots" analysis would accountable for smaller technical variation.

Second, analysing NMRI mice brain proteome, the proportion of biological and technical variation in total variation was estimated. These results indicate that the technical variance predominates in total variation. As these results characterise the anticipated variation using mouse brain for proteomic study hence they should be useful for future experimental design in other proteomics laboratories

Third, the effect of the genetic background on the total variation of mouse brain proteome was investigated. For this purpose I compared the variations of brain proteome profiles of littermate and non-littermate NMRI mice groups. The results displayed only a small difference. It suggests that genetic background has a negligible effect on the brain proteome profile when NMRI mouse stock is used. A comparison of the total variance of an out-bred mouse stock (NMRI) and an inbred mouse strain (C3H/HEN) also reveals a small genetic influence on the total variance, as the calculated total variance values are very similar in both populations. However, the power calculation indicates that a higher sample size would be appropriate to detect smaller differences. In addition the detection limit of the 2-DE should be taken into account. It can be assumed, that the analysed 446 protein spots belong to the highabundant proteins. Thus a different variation could be observed analysing other subset of proteome, such as low-abundant proteins. It can be also assumed that the biological variation of other organs or other model systems may differ from the mouse brain proteome. Anyway, these results suggest that the random selection of animals as generally used in animal experimental design is feasible for neuroproteomic studies as well.

Fourth, pairwise comparisons suggest that using mice which are born in a short period of time is recommended, as no significant protein expression differences were found from analysing these groups of mice. These results reveal that the 2-DE workflow has a good reproducibility. The results also suggest that the gel-to-gel variation can be reduced by processing the samples in a short period of time. My 2-DE studies also demonstrate that a well standardized 2-DE workflow followed by a much cheaper post-stain (RuBPs) could be useable to detect higher protein expression changes (e.g. 1.5- or 2-fold change), especially using animal models or cell lines with a relatively low biological variation. 
Fifth, deeper statistical analysis reveals the importance of using different statistical approaches as different results can be obtained depending on the statistical tools. Controlling not only the type-I, but the type-II error rate and applying multiple test approaches (FDR, SGoF) are fully recommended. These statistical tools may help to avoid false discoveries, missing true differences and improve the statistical validity of the results got from a 2-DE study. However, the accepted significance cut-off values greatly depend on the user's choice. The difference arose from statistical approaches could be observed analysing either mouse brain or SH-SY5Y cell lysate.

Sixth, using quantitative 2-DE, I studied the effect of oligomeric A $\beta 1-42$ in situ prepared from the precursor peptide "iso-A $\beta 1-42$ ". In this experiment, differentiated SH-SY5Y neuroblastoma cells were treated with $A \beta 1-42$. Numerous proteins displayed significantly changed expression. Moreover, two of the most striking differences (Hsp70 and EEF2) were validated by Western blot analysis. This may confirm the results got from the 2-DE analysis.

Seventh, the functional classification shows that most of the identified proteins play a role in TCA, energy production, cytoskeleton organisation, protein biosynthesis and the relatively high number of stress-related proteins reveals dramatic cellular stress induced by oligomeric $\mathrm{A} \beta 1$-42. Most of these cellular processes have already been related to A $\beta 1-42$-mediated cellular stress and subsequent cell death. The strong display of ER chaperones may indicate that $A \beta 1-42$ induced ER stress. It is well known that ER plays a crucial role in cellular $\mathrm{Ca}^{2+}$ homeostasis and proper protein folding process. In addition, a significant portion of the downregulated proteins play a role in protein biosynthetic processes. It is in accordance with the ER stress. Serious or prolonged ER stress could induce cell death, thus further analysis of the related molecular pathways may help to understand the mechanism of cell death induced by A 1 1-42. 


\section{Acknowledgements}

I am grateful to Prof. Botond Penke for allowing me to join his research group and for giving an opportunity to me to perform my experiments.

I would like express my gratitude to Dr. Tamás Janáky for scientific guidance, encouragement and support during my Ph.D. course.

I would like to thank everyone who helped me to perform these experiments and provided useful technical support: Dr. Gábor Juhász, Dr. Datki L. Zsolt, Dr. Bozsó Zsolt, Dr. Zoltán Szabó, József Klem, Rita Szendrei, Dóra Simon, Szilvia Pataki, Emese Mózes and Anikó M. Tóth.

I would like to thank all members of the Alzheimer's Disease Research Group and the Department of Medical Chemistry.

Finally, I am especially thankful to Adri and my family for their love and encouragement.

The research was supported by the following grants: OTKA NK 73672 from the Hungarian National Sciences Foundation; Memoload FP-7 201159; Lipididiet FP-7 211696 and TAMOP 4.2.2 project. 


\section{References}

Alban A., David S. O., Bjorkesten L., et al. (2003) A novel experimental design for comparative twodimensional gel analysis: two-dimensional difference gel electrophoresis incorporating a pooled internal standard. Proteomics 3, 36-44.

Anderson N. L. and Anderson N. G. (2002) The human plasma proteome: history, character, and diagnostic prospects. Mol Cell Proteomics 1, 845-867.

Anelli T., Alessio M., Mezghrani A., et al. (2002) ERp44, a novel endoplasmic reticulum folding assistant of the thioredoxin family. The EMBO journal 21, 835-844.

Ansari M. A. and Scheff S. W. (2010) Oxidative stress in the progression of Alzheimer disease in the frontal cortex. J Neuropathol Exp Neurol 69, 155-167.

Appel R. D., Vargas J. R., Palagi P. M., et al. (1997) Melanie II--a third-generation software package for analysis of two-dimensional electrophoresis images: I. Algorithms. Electrophoresis 18, 2724-2734.

Asirvatham V. S., Watson B. S. and Sumner L. W. (2002) Analytical and biological variances associated with proteomic studies of Medicago truncatula by two-dimensional polyacrylamide gel electrophoresis. Proteomics 2, 960-968.

Bayes A. and Grant S. G. (2009) Neuroproteomics: understanding the molecular organization and complexity of the brain. Nat Rev Neurosci 10, 635-646.

Benjamini, Y. and Hochberg, Y. (1995) Controlling the false discovery rate: a practical and powerful approach to multiple testing. J Roy Stat Soc B Met 57, 289-300.

Berggren K., Chernokalskaya E., Steinberg T. H., et al. (2000) Background-free, high sensitivity staining of proteins in one- and two-dimensional sodium dodecyl sulfate-polyacrylamide gels using a luminescent ruthenium complex. Electrophoresis 21, 2509-2521.

Bjellqvist B., Ek K., Righetti P. G., Gianazza E., et al. (1982) Isoelectric focusing in immobilized pH gradients: principle, methodology and some applications. J Biochem Biophys Methods 6, 317-339.

Blennow K., de Leon M. J. and Zetterberg H. (2006) Alzheimer's disease. Lancet 368, 387-403.

Bomsztyk K., Denisenko O. and Ostrowski J. (2004) hnRNP K: one protein multiple processes. Bioessays 26, 629-638.

Bozso Z., Penke B., Simon D., et al. (2010) Controlled in situ preparation of A beta(1-42) oligomers from the isopeptide "iso-A beta(1-42)", physicochemical and biological characterization. Peptides 31, 248-256.

Bubber P., Haroutunian V., Fisch G., et al. (2005) Mitochondrial abnormalities in Alzheimer brain: mechanistic implications. Ann Neurol 57, 695-703.

Candiano G., Bruschi M., Musante L., et al. (2004) Blue silver: a very sensitive colloidal Coomassie G-250 staining for proteome analysis. Electrophoresis 25, 1327-1333.

Carpentier S. C., Panis B., Swennen R., et al. (2008) Finding the significant markers: statistical analysis of proteomic data. Methods MolBiol 428, 327-347.

Carvajal-Rodriguez A., de Una-Alvarez J. and Rolan-Alvarez E. (2009) A new multitest correction (SGoF) that increases its statistical power when increasing the number of tests. BMC bioinformatics 10, 209.

Chafekar S. M., Hoozemans J. J., Zwart R., et al. (2007) Abeta 1-42 induces mild endoplasmic reticulum stress in an aggregation state-dependent manner. Antioxid Redox Signal 9, 2245-2254.

Cho J. H. and Johnson G. V. (2004) Glycogen synthase kinase 3 beta induces caspase-cleaved tau aggregation in situ. J Biol Chem 279, 54716-54723.

Clark B. N. and Gutstein H. B. (2008) The myth of automated, high-throughput two-dimensional gel analysis. Proteomics 8, 1197-1203.

Crouch P. J., Harding S. M., White A. R., et al. (2008) Mechanisms of A beta mediated neurodegeneration in Alzheimer's disease. Int J Biochem Cell Biol 40, 181-198.

Daniel W.W. (2005) Biostatistics ( $8^{\text {th }}$ edition). John Wiley \& Sons, Inc., Hoboken, NJ, USA

Datki Z., Juhasz A., Galfi M., et al. (2003) Method for measuring neurotoxicity of aggregating polypeptides with the MTT assay on differentiated neuroblastoma cells. Brain Res Bull 62, 223-229.

David D. C., Ittner L. M., Gehrig P., et al. (2006) Beta-amyloid treatment of two complementary P301L tauexpressing Alzheimer's disease models reveals similar deregulated cellular processes. Proteomics 6, 65666577.

Davidsson P. and Sjogren M. (2006) Proteome studies of CSF in AD patients. Mech Ageing Dev 127, 133-137.

de Hoog C. L. and Mann M. (2004) Proteomics. Annu Rev Genomics Hum Genet 5, 267-293.

Demuro A., Parker I. and Stutzmann G. E. (2010) Calcium signaling and amyloid toxicity in Alzheimer disease. J Biol Chem 285, 12463-12468. 
Di Carlo M., Picone P., Carrotta R., et al. (2010) Insulin promotes survival of amyloid-beta oligomers neuroblastoma damaged cells via caspase 9 inhibition and Hsp70 upregulation. J Biomed Biotechnol 2010, 147835 .

Di Domenico F., Sultana R., Tiu G. F., et al. (2010) Protein levels of heat shock proteins 27, 32, 60, 70, 90 and thioredoxin-1 in amnestic mild cognitive impairment: an investigation on the role of cellular stress response in the progression of Alzheimer disease. Brain Res 1333, 72-81.

Diz A. P., Carvajal-Rodriguez A. and Skibinski D. O. (2010) Multiple hypothesis testing in proteomics: A strategy for experimental work. Mol Cell Proteomics. doi:10.1074/mcp.0110.004374

Dowsey A. W., Morris J. S., Gutstein H. B. et al. (2010) Informatics and statistics for analyzing 2-d gel electrophoresis images. Methods Mol Biol 604, 239-255.

Eng J.K., McCormack A.L. and Yates J.R. (1994) An approach to correlate tandem mass spectral data of peptides with amino acid sequences in a protein database. J Am Soc Mass Spectrom 5, 976-989.

Fenn J.B., Mann M., Meng C.K., et al. (1989) Electrospray ionization for mass spectrometry of large biomolecules. Science 246, 64-71.

Finehout E. J., Franck Z., Choe L. H., et al. (2007) Cerebrospinal fluid proteomic biomarkers for Alzheimer's disease. Ann Neurol 61, 120-129.

Friedman D. B., Hoving S. and Westermeier R. (2009) Isoelectric focusing and two-dimensional gel electrophoresis. Methods Enzymol 463, 515-540.

Garbis S., Lubec G. and Fountoulakis M. (2005) Limitations of current proteomics technologies. J Chromatog 1077, 1-18.

Gibbs R. A., Weinstock G. M., Metzker M. L., et al. (2004) Genome sequence of the Brown Norway rat yields insights into mammalian evolution. Nature 428, 493-521.

Gorg A., Drews O., Luck C., et al. (2009) 2-DE with IPGs. Electrophoresis 30 Suppl 1, S122-132.

Granvogl B., Plöscher M., Eichacker L.A. (2007) Sample preparation by in-gel digestion for mass spectrometrybase proteomics. Anal Bioanal Chem 389,991-1002.

Gustafsson J. S., Ceasar R., Glasbey C. A., et al. (2004) Statistical exploration of variation in quantitative twodimensional gel electrophoresis data. Proteomics 4, 3791-3799.

Gygi S. P., Rochon Y., Franza B. R., et al. (1999) Correlation between protein and mRNA abundance in yeast. Mol Cell Biol 19, 1720-1730.

Haass C. and Selkoe D. J. (2007) Soluble protein oligomers in neurodegeneration: lessons from the Alzheimer's amyloid beta-peptide. Nat Rev Mol Cell Biol 8, 101-112.

Hamacher M., Stephan C., Eisenacher M., et al. (2008) Maintaining standardization: an update of the HUPO Brain Proteome Project. Exp Rev Proteomics 5, 165-173.

Hardy J. A. and Higgins G. A. (1992) Alzheimer's disease: the amyloid cascade hypothesis. Science 256, 184185.

Heinitz K., Beck M., Schliebs R., et al. (2006) Toxicity mediated by soluble oligomers of beta-amyloid(1-42) on cholinergic SN56.B5.G4 cells. J Neurochem 98, 1930-1945.

Heneka M. T. and O'Banion M. K. (2007) Inflammatory processes in Alzheimer's disease. J Neuroimmunol 184, 69-91.

Hernandez F., de Barreda E. G., Fuster-Matanzo A., et al. (2009) The role of GSK3 in Alzheimer disease. Brain Res Bull 80, 248-250.

Holm S., (1979) A simple sequentially rejective multiple test procedure. Scand J Stat 6, 65-70.

Horgan G. W. (2007) Sample size and replication in 2D gel electrophoresis studies. J Proteome Res 6, $2884-$ 2887.

Hunt S. M., Thomas M. R., Sebastian L. T., et al. (2005) Optimal replication and the importance of experimental design for gel-based quantitative proteomics. J Proteome Res 4, 809-819.

Hynd M. R., Scott H. L. and Dodd P. R. (2004) Glutamate-mediated excitotoxicity and neurodegeneration in Alzheimer's disease. Neurochem Int 45, 583-595.

Ibel K., May R. P., Kirschner K., et al. (1990) Protein-decorated micelle structure of sodium-dodecyl-sulfate-protein complexes as determined by neutron scattering. Eur J Biochem/FEBS 190, 311-318.

Inagaki N., Chihara K., Arimura N., et al. (2001) CRMP-2 induces axons in cultured hippocampal neurons. Nat Neurosci 4, 781-782.

Irvine G. B., El-Agnaf O. M., Shankar G. M., et al. (2008) Protein aggregation in the brain: the molecular basis for Alzheimer's and Parkinson's diseases. Mol Med 14, 451-464.

Ittner L. M. and Gotz J. (2011) Amyloid-beta and tau--a toxic pas de deux in Alzheimer's disease. Nat Rev Neurosci 12, 65-72.

James P., Quadroni M., Carafoli E., et al. (1993) Protein identification by mass profile fingerprinting. Biochem Biophys Res Commun 195, 58-64. 
Joerchel S., Raap M., Bigl M., et al. (2008) Oligomeric beta-amyloid(1-42) induces the expression of Alzheimer disease-relevant proteins in cholinergic SN56.B5.G4 cells as revealed by proteomic analysis. Int J Dev Neurosci 26, 301-308.

Juhasz G., Foldi I. and Penke B. (2011) Systems biology of Alzheimer's disease: How diverse molecular changes result in memory impairment in AD. Neurochem Int doi:10.1016/j.neuint.2011.02.008

Kang Y., Techanukul T., Mantalaris A., et al. (2009) Comparison of three commercially available DIGE analysis software packages: minimal user intervention in gel-based proteomics. J Proteome Res 8, 10771084.

Karas M., Bachmann D., Bahr U., et al. (1987) Matrix-assisted ultraviolet laser desorption of non-voltile compounds. Int J Mass Spectrom Ion Proc 78,53-68.

Karp N. A. and Lilley K. S. (2007) Design and analysis issues in quantitative proteomics studies. Proteomics 7 Suppl 1, 42-50.

Karp N. A. and Lilley K. S. (2009) Investigating sample pooling strategies for DIGE experiments to address biological variability. Proteomics 9, 388-397.

Karp N. A., Feret R., Rubtsov D. V., et al. (2008) Comparison of DIGE and post-stained gel electrophoresis with both traditional and SameSpots analysis for quantitative proteomics. Proteomics 8, 948-960.

Karp N. A., Spencer M., Lindsay H., et al. (2005) Impact of replicate types on proteomic expression analysis. $J$ Proteome Res 4, 1867-1871.

Kimura E., Abe K., Suzuki K., et al. (2003) Heterogeneous nuclear ribonucleoprotein K interacts with and is proteolyzed by calpain in vivo. Biosci Biotechnol Biochem 67, 1786-1796.

Kimura Y., Nagata K., Suzuki N., et al. (2010) Characterization of multiple alternative forms of heterogeneous nuclear ribonucleoprotein K by phosphate-affinity electrophoresis. Proteomics 10, 3884-3895.

Koren J., 3rd, Jinwal U. K., Lee D. C., et al. (2009) Chaperone signalling complexes in Alzheimer's disease. J Cell Mol Med 13, 619-630.

Korolainen M. A., Nyman T. A., Aittokallio T., et al. (2010) An update on clinical proteomics in Alzheimer's research. J Neurochem 112, 1386-1414.

Laemmli U. K. (1970) Cleavage of structural proteins during the assembly of the head of bacteriophage T4. Nature 227, 680-685.

LaFerla F. M., Green K. N. and Oddo S. (2007) Intracellular amyloid-beta in Alzheimer's disease. Nat Rev Neurosci 8, 499-509.

Lamberty Y. and Gower A. J. (1992) Age-related changes in spontaneous behavior and learning in NMRI mice from middle to old age. Physiol Behav 51, 81-88.

Lander E. S., Linton L. M., Birren B., et al. (2001) Initial sequencing and analysis of the human genome. Nature 409, 860-921.

Lee do Y., Lee K. S., Lee H. J., et al. (2010) Activation of PERK signaling attenuates Abeta-mediated ER stress. PloS one 5, e10489.

Lenth R. V. (2007) Statistical power calculations. J Anim Sci 85, E24-29.

Li X., Alafuzoff I., Soininen H., et al. (2005) Levels of mTOR and its downstream targets 4E-BP1, eEF2, and eEF2 kinase in relationships with tau in Alzheimer's disease brain. The FEBS journal 272, 4211-4220.

Ma Y. and Hendershot L. M. (2004) ER chaperone functions during normal and stress conditions. J Chem Neuroanat 28, 51-65.

Maarouf C. L., Andacht T. M., Kokjohn T. A., et al. (2009) Proteomic analysis of Alzheimer's disease cerebrospinal fluid from neuropathologically diagnosed subjects. Cur Alzheimer Res 6, 399-406.

Mariani E., Polidori M. C., Cherubini A., et al. (2005) Oxidative stress in brain aging, neurodegenerative and vascular diseases: an overview. J Chromatogr B Analyt Technol Biomed Life Sci 827, 65-75.

Meunier L., Usherwood Y. K., Chung K. T., et al. (2002) A subset of chaperones and folding enzymes form multiprotein complexes in endoplasmic reticulum to bind nascent proteins. Mo Biol Cell 13, 4456-4469.

Meyer H. E. and Stuhler K. (2007) High-performance proteomics as a tool in biomarker discovery. Proteomics 7 Suppl 1, 18-26.

Miller I., Crawford J. and Gianazza E. (2006) Protein stains for proteomic applications: which, when, why? Proteomics 6, 5385-5408.

Miura K. (2001) Imaging and detection technologies for image analysis in electrophoresis. Electrophoresis 22, 801-813.

Molloy M. P., Brzezinski E. E., Hang J., et al. (2003) Overcoming technical variation and biological variation in quantitative proteomics. Proteomics 3, 1912-1919.

Moskophidis D. and Lehmann-Grube F. (1983) The immune response of the mouse to lymphocytic choriomeningitis virus. III. Differences of numbers of cytotoxic T lymphocytes in spleens of mice of different strains. Cell Immunol 77, 279-289. 
Nagy S., Adamicza Á., Boros M., et al. (2007) Animal experiments in medicine. Handbook for medical students. University of Szeged, Szeged, Hungary

Nie L., Wu G., Culley D. E., Scholten J. C., et al. (2007) Integrative analysis of transcriptomic and proteomic data: challenges, solutions and applications. Cri Rev Biotechnol 27, 63-75.

Oakley B. R., Kirsch D. R. and Morris N. R. (1980) A simplified ultrasensitive silver stain for detecting proteins in polyacrylamide gels. Anal Biochem 105, 361-363.

O'Farrell P. H. (1975) High resolution two-dimensional electrophoresis of proteins. J Biol Chem 250, 4007 4021.

Pereira C., Agostinho P., Moreira P. I., et al. (2005) Alzheimer's disease-associated neurotoxic mechanisms and neuroprotective strategies. Cur Drug Targets 4, 383-403.

Petrak J., Ivanek R., Toman O., et al. (2008) Deja vu in proteomics. A hit parade of repeatedly identified differentially expressed proteins. Proteomics 8, 1744-1749.

Philipson O., Lord A., Gumucio A., et al. (2010) Animal models of amyloid-beta-related pathologies in Alzheimer's disease. The FEBS journal 277, 1389-1409.

Picone P., Carrotta R., Montana G., et al. (2009) Abeta oligomers and fibrillar aggregates induce different apoptotic pathways in LAN5 neuroblastoma cell cultures. Biophys $J$ 96, 4200-4211.

Pithukpakorn M. (2005) Disorders of pyruvate metabolism and the tricarboxylic acid cycle. Mol Genet Metab 85, 243-246.

Pratico D. (2008) Evidence of oxidative stress in Alzheimer's disease brain and antioxidant therapy: lights and shadows. Ann N Y Acad Sci 1147, 70-78.

Rabilloud T. (2002) Two-dimensional gel electrophoresis in proteomics: old, old fashioned, but it still climbs up the mountains. Proteomics 2, 3-10.

Rabilloud T., Chevallet M., Luche S., et al. (2010) Two-dimensional gel electrophoresis in proteomics: Past, present and future. J Proteomics 73, 2064-2077.

Rabilloud T., Strub J. M., Luche S., et al. (2001) A comparison between Sypro Ruby and ruthenium II tris (bathophenanthroline disulfonate) as fluorescent stains for protein detection in gels. Proteomics 1, 699-704.

Reiner A., Yekutieli D. and Benjamini Y. (2003) Identifying differentially expressed genes using false discovery rate controlling procedures. Bioinformatics 19, 368-375.

Rhein V., Baysang G., Rao S., et al. (2009) Amyloid-beta leads to impaired cellular respiration, energy production and mitochondrial electron chain complex activities in human neuroblastoma cells. Cell Mol Neurobiol 29, 1063-1071.

Richert S., Luche S., Chevallet M., Van Dorsselaer A., et al. (2004) About the mechanism of interference of silver staining with peptide mass spectrometry. Proteomics 4, 909-916.

Righetti P. G. and Drysdale J. W. (1973) Small-scale fractionation of proteins and nucleic acids by isoelectric focusing in polyacrylamide gels. Ann N Y Acad Sci 209, 163-186.

Schonberger S. J., Edgar P. F., Kydd R., et al. (2001) Proteomic analysis of the brain in Alzheimer's disease: molecular phenotype of a complex disease process. Proteomics 1, 1519-1528.

Shaw J., Rowlinson R., Nickson J., et al. (2003) Evaluation of saturation labelling two-dimensional difference gel electrophoresis fluorescent dyes. Proteomics 3, 1181-1195.

Shevchenko A., Wilm M., Vorm O., et al. (1996) Mass spectrometric sequencing of proteins silver-stained polyacrylamide gels. Anal Chem 68, 850-858.

Silva E., O'Gorman M., Becker S., et al. (2010) In the eye of the beholder: does the master see the SameSpots as the novice? J Proteome Res 9, 1522-1532.

Sohma Y., Hayashi Y., Skwarczynski M., et al. (2004) O-N intramolecular acyl migration reaction in the development of prodrugs and the synthesis of difficult sequence-containing bioactive peptides. Biopolymers 76, 344-356.

Sowell R. A., Owen J. B. and Butterfield D. A. (2009) Proteomics in animal models of Alzheimer's and Parkinson's diseases. Ageing Res Rev 8, 1-17.

Steele K. E., Davis K. J., Stephan K., et al. (1998) Comparative neurovirulence and tissue tropism of wild-type and attenuated strains of Venezuelan equine encephalitis virus administered by aerosol in $\mathrm{C} 3 \mathrm{H} / \mathrm{HeN}$ and BALB/c mice. Vet Pathol 35, 386-397.

Steinberg T. H. (2009) Protein gel staining methods: an introduction and overview. Methods Enzymol 463, 541563.

Steinberg T. H., Haugland R. P. and Singer V. L. (1996) Applications of SYPRO orange and SYPRO red protein gel stains. Anal Biochem 239, 238-245.

Stessl M., Noe C. R. and Lachmann B. (2009) Influence of image-analysis software on quantitation of twodimensional gel electrophoresis data. Electrophoresis 30, 325-328. 
Stone K.L., DeAngelis R., LoPresti M., et al. (1998) Use of liquid chromtography-electrospray ionizationtandem mass spectrometry (LC-ESI-MS/MS) for routine identification of enzymatically digested proteins separated by sodium dodecyl sulfate-polyacrylamide gel electrophoresis. Electrophoresis 19, 1046-1052.

Storey, J. D. (2002) A direct approach to false discovery rates. J Roy Stat Soc B 64, 479-498.

Storey, J. D. and Tibshirani, R. (2003) Statistical significance for genome-wide studies. Proc Natl Acad Sci U.S.A 100, 9440-9445.

Sultana R., Boyd-Kimball D., Cai J., Pierce W. M., et al. (2007) Proteomics analysis of the Alzheimer's disease hippocampal proteome. J Alzheimers Dis 11, 153-164.

Switzer R. C., 3rd, Merril C. R. and Shifrin S. (1979) A highly sensitive silver stain for detecting proteins and peptides in polyacrylamide gels. Anal Biochem 98, 231-237.

Tonge R., Shaw J., Middleton B., et al. (2001) Validation and development of fluorescence two-dimensional differential gel electrophoresis proteomics technology. Proteomics 1, 377-396.

Tsuji T., Shiozaki A., Kohno R., et al. (2002) Proteomic profiling and neurodegeneration in Alzheimer's disease. Neurochem Res 27, 1245-1253.

Unlu M., Morgan M. E. and Minden J. S. (1997) Difference gel electrophoresis: a single gel method for detecting changes in protein extracts. Electrophoresis 18, 2071-2077.

Valledor L. and Jorrin J. (2011) Back to the basics: Maximizing the information obtained by quantitative two dimensional gel electrophoresis analyses by an appropriate experimental design and statistical analyses. $J$ Proteomics 74, 1-18.

Venter J. C., Adams M. D., Myers E. W., et al. (2001) The sequence of the human genome. Science 291, 13041351.

Verdier Y., Zarandi M. and Penke B. (2004) Amyloid beta-peptide interactions with neuronal and glial cell plasma membrane: binding sites and implications for Alzheimer's disease. J Pept Sci 10, 229-248.

Vesterberg O. (1972) Isoelectric focusing of proteins in polyacrylamide gels. Biochim Biophys Acta 257, 11-19.

Vesterberg O. and Svensson H. (1966) Isoelectric fractionation, analysis, and characterization of ampholytes in natural $\mathrm{pH}$ gradients. IV. Further studies on the resolving power in connection with separation of myoglobins. Acta Chem Scand 20, 820-834.

Walsh D. M. and Selkoe D. J. (2004) Deciphering the molecular basis of memory failure in Alzheimer's disease. Neuron 44, 181-193.

Waterston R. H., Lindblad-Toh K., Birney E., et al. (2002) Initial sequencing and comparative analysis of the mouse genome. Nature 420, 520-562.

Westermeier R. and Naven T. (2002) Proteomics in practice. Wiley-VCH Verlag-Gmbh, Weinheim, Germany

Wheelock A. M. and Buckpitt A. R. (2005) Software-induced variance in two-dimensional gel electrophoresis image analysis. Electrophoresis 26, 4508-4520.

Wheelock A. M. and Goto S. (2006) Effects of post-electrophoretic analysis on variance in gel-based proteomics. Exp Rev Proteomics 3, 129-142.

White M. C., Gao R., Xu W., et al. (2010) Inactivation of hnRNP K by expanded intronic AUUCU repeat induces apoptosis via translocation of PKCdelta to mitochondria in spinocerebellar ataxia 10. PLoS genetics 6, e1000984.

Wilkins M. R., Sanchez J. C., Gooley A. A., et al. (1996) Progress with proteome projects: why all proteins expressed by a genome should be identified and how to do it. Biotechnol Genet Eng Rev 13, 19-50.

Wilm M., Shevchenko A., Houthhaeve T., et al. (1996) Femtomole sequencing of proteins from polyacrylamide gels by nano-electrospray mass spectrometry. Nature 379, 466-469.

Winkler W., Zellner M., Diestinger M., et al. (2008) Biological variation of the platelet proteome in the elderly population and its implication for biomarker research. Mol Cell Proteomics 7, 193-203.

Wu T. L. (2006) Two-dimensional difference gel electrophoresis. Methods Mol Biol 328, 71-95.

Xu C., Bailly-Maitre B. and Reed J. C. (2005) Endoplasmic reticulum stress: cell life and death decisions. J Clin Invest 115, 2656-2664.

Yan W. and Chen S. S. (2005) Mass spectrometry-based quantitative proteomic profiling. Brief Funct Genomic Proteomic 4, 27-38.

Yao J., Irwin R. W., Zhao L., et al. (2009) Mitochondrial bioenergetic deficit precedes Alzheimer's pathology in female mouse model of Alzheimer's disease. Proc Natl Acad Sci USA 106, 14670-14675.

Zhang X., Guo Y., Song Y., et al. (2006) Proteomic analysis of individual variation in normal livers of human beings using difference gel electrophoresis. Proteomics 6, 5260-5268.

Zuo X., Echan L., Hembach P., Tang H. Y., et al. (2001) Towards global analysis of mammalian proteomes using sample prefractionation prior to narrow $\mathrm{pH}$ range two-dimensional gels and using one-dimensional gels for insoluble and large proteins. Electrophoresis 22, 1603-1615. 